UNIVERSIDADE DE SÃO PAULO

ESCOLA DE ENFERMAGEM

MARIANA ALVINA DOS SANTOS

FATORES ASSOCIADOS AO PADRÃO DE SONO DE PACIENTES COM INSUFICIÊNCIA CARDÍACA

SÃO PAULO

2010 
MARIANA ALVINA DOS SANTOS

\section{FATORES ASSOCIADOS AO PADRÃO DE SONO DE PACIENTES COM INSUFICIÊNCIA CARDÍACA}

Dissertação apresentada à Escola de Enfermagem da Universidade de São Paulo para obtenção do título de Mestre em Ciências.

Área de Concentração:

Enfermagem na Saúde do Adulto

Orientadora:

Profa $^{\text {. Dr }}{ }^{\mathrm{a}}$. Diná de Almeida L. M. da Cruz 
AUTORIZO A REPRODUÇÃO TOTAL OU PARCIAL DESTE TRABALHO, POR QUALQUER MEIO CONVENCIONAL OU ELETRÔNICO, PARA FINS DE ESTUDO E PESQUISA, DESDE QUE CITADA A FONTE.

Assinatura: Data

\section{Catalogação na Publicação (CIP)}

Biblioteca "Wanda de Aguiar Horta"

Escola de Enfermagem da Universidade de São Paulo

Santos, Mariana Alvina dos.

Fatores associados ao padrão de sono de pacientes com insuficiência cardíaca / Mariana Alvina dos Santos. - São Paulo, 2010 .

$101 \mathrm{p}$.

Dissertação (Mestrado) - Escola de Enfermagem da Universidade de São Paulo.

Orientadora: Prof ${ }^{a}$ Dr $^{a}$ Diná de Almeida Monteiro Lopes da Cruz.

1. Sono (qualidade) 2. Insuficiência cardíaca (complicações) 3. Dispnéia. 4. Enfermagem. I.Título. 


\section{FOLHA DE APROVAÇÃO}

Nome: MARIANA ALVINA DOS SANTOS

Título: FATORES ASSOCIADOS AO PADRÃO DE SONO DE PACIENTES COM INSUFICIÊNCIA CARDÍACA

Dissertação apresentada à Escola de Enfermagem da Universidade de São Paulo, para obtenção do título de Mestre em Ciências.

Aprovada em:

\section{Banca Examinadora}

Prof. Dr. Instituição:

Julgamento:

Assinatura:

Prof. Dr. Instituição:

Julgamento:

Assinatura:

Prof. Dr.

Instituição:

Julgamento:

Assinatura: 
Porque Dele, por Ele e para Ele são todas as coisas. A Ele pois, a glória eternamente. Amém. Romanos 11:36. 


\section{Agradecimentos}

Este estudo representa a união de desejos, sonhos e encorajamento constantes que recebi durante sua realização. A confiança e força depositadas em meu nome, ajudaram-me a superar obstáculos vivenciados durante a realização deste trabalho, a aprimorar-me profissionalmente, além de propiciar um grande crescimento pessoal.

Não me resta a menor dúvida, que parte importante deste trabalho não poderia ter sido executada sem a imprescindível participação de pessoas especiais, com a quais Deus me deu o privilégio de poder conviver:

À minha querida mãe, Raimunda Alvina, por me ensinar a não desistir nunca dos meus objetivos, pelo amor que recebo todos os dias, por me proporcionar as mais sábias lições, inclusive a maior delas: "Deus está no controle de todas as coisas, minha filha".

À Profa Dra $^{a}$ Diná de Almeida L. M. da Cruz, pela orientação deste trabalho, pelo apoio e carinho em TODOS os momentos vivenciados durante sua realização e, principalmente, pelos ensinamentos constantes que me fazem almejar uma Enfermagem de excelência.

Ao Instituto Dante Pazzanese de Cardiologia, especialmente ao Serviço de Educação Continuada e ao Ambulatório de Insuficiência Cardíaca, por ter tornado possível a realização deste trabalho.

Ao Ricardo Luís Barbosa, do Laboratório de Bioestatística da Escola de Enfermagem, pela disponibilidade em atender-me e orientar-me com tamanha capacitação.

Ao meu querido Amigo Marcelo, pelo carinho de todas as horas, pelo apoio e incentivo decisivos na realização desta tarefa e, principalmente, por me ensinar a levar a vida de forma mais leve.

Aos amados Amigos : Adriana Magalhães, Caroline, Denysia, Fernanda, Paula, Sheila e Vinícius, vocês são as mais belas flores que enfeitam o meu jardim; contar com a amizade de vocês é um presente!!

Aos meus tios, Regina e Darci, pelo carinho e afeto que recebo de vocês. 
À minha família, que somou amor e estímulo aos meus esforços, por apoiarem as minhas escolhas.

Às companheiras de pós-graduação, Érika Guedes e Fabiana Matos, por caminharem ao meu lado.

Aos colegas do Grupo de Pesquisa DIRENF (Diagnósticos, Intervenções e Resultados de Enfermagem), pelas valiosas contribuições.

Aos funcionários da Secretaria de Pós-Graduação, Silvana, Regiane, Dayse e Renata; da Secretaria do Departamento ENC e da Biblioteca da Escola de Enfermagem, pela disponibilidade em me ajudar.

À Fundação de Amparo à Pesquisa do Estado de São Paulo (FAPESP), pelo auxílio financeiro concedido ao projeto.

Último e mais importante: aos pacientes, que com boa vontade participaram deste estudo.

A todos, minha gratidão. 
“Bom mesmo é ir à luta com determinação, abraçar a vida com paixão, perder com classe e vencer com ousadia, pois o triunfo pertence a quem se atreve, e a vida é muito boa para ser insignificante." 
Santos MA. Fatores associados ao padrão de sono de pacientes com insuficiência cardíaca [dissertação]. São Paulo: Escola de Enfermagem, Universidade de São Paulo; 2010.

\section{RESUMO}

INTRODUÇÃO: A insuficiência cardíaca (IC) constitui hoje um dos maiores problemas de saúde pública em todo o mundo, com números crescentes em qualquer análise epidemiológica. Além de representar grande demanda aos serviços de saúde, é responsável por prejuízo na qualidade de vida das pessoas. Alterações do sono têm sido descritas como freqüentes e comuns entre os pacientes com IC, e também é um dos sintomas de mais incômodo para esta população. OBJETIVO: Descrever o padrão de sono em pacientes com IC e analisar associações do padrão de sono com as seguintes variáveis: sexo, idade, fadiga, fadiga ao esforço, atividade física, classe funcional, terapia medicamentosa, dispnéia e índice de massa corporal. MÉTODO: Estudo transversal descritivo, com uma amostra não probabilística de 400 pacientes ambulatoriais (idade média 57,8 anos, $\mathrm{DP}=11,6 ; 64,8 \%$ eram homens; escolaridade média de 6,1 anos, $\mathrm{DP}=3,9$; $82,5 \%$ em classe funcional II ou III) em tratamento de insuficiência cardíaca em um hospital de ensino. Os dados foram coletados por meio de entrevista em que os participantes responderam a um conjunto de instrumentos contendo: dados de demográficos e da insuficiência cardíaca; e avaliação do padrão de sono (Pittsburg Sleep Quality Index PSQI); de fadiga (Dutch Fatigue Scale - DUFS), fadiga ao esforço (Dutch Exertion Fatigue Scale), atividade física (International Physical Activity Questionnaire) e dados sobre dispnéia, tabagismo e terapia medicamentosa. Os instrumentos mostraram boa consistência interna na amostra deste estudo (no PSQI $\alpha=0,73$; na DUFS $\alpha=0,90$ e na DEFS $\alpha=0,92$ ). Testes não paramétricos foram aplicados para analisar a associação do padrão de sono com variáveis selecionadas e um modelo de regressão logística foi ajustado para investigar os preditores de maus dormidores. RESULTADOS: O escore total médio no PSQI foi 8,70 (DP = 4,39); a prevalência de maus dormidores (PSQI > 5) foi de $68,5 \%$; e $46,5 \%$ classificou o sono como ruim ou muito ruim. Escores mais elevados no PSQI ou categoria de mau dormidor foram associados com: sexo feminino $(p=0,009)$; não empregados $(p=0,013)$, fadiga $(p=0,000)$, fadiga ao esforço $(p=0,000)$, dispnéia $(p=0,000)$ e classes funcionais mais elevadas da IC $(p=0,000)$. Dispnéia (OR $=3,23$; IC95\% $1,72-6,07)$ e fadiga $(\mathrm{OR}=3,45 ;$ IC95\%1,82 - 6,49) associaram-se independentemente à categoria de mau dormidor. CONCLUSÕES: A proporção de maus dormidores entre os pacientes com IC está entre as mais altas nas doenças crônicas. Dispnéia e fadiga, sintomas comuns nessa enfermidade, aumentam significativamente a chance de ser mau dormidor. Portanto, o padrão do sono dos pacientes com IC deve ser rotineiramente avaliado.

Palavras-chave: Enfermagem, Sono, Insuficiência Cardíaca, Fadiga, Dispnéia. 
Santos MA. Factors associated with sleep pattern of patients with heart failure [dissertation]. São Paulo: Escola de Enfermagem, Universidade de São Paulo; 2010.

\begin{abstract}
INTRODUCTION: Heart failure (HF) is one of the largest public health problems worldwide, with increasing numbers in any epidemiological analysis. Besides representing a large demand for health services, it is responsible for poor quality of life. Sleep disorders have been described as frequent and common among patients with HF, as well as one of the most troublesome symptoms for this population. OBJECTIVE: To describe sleep patterns in patients with $\mathrm{HF}$ and examine associations of sleep pattern with the following variables: gender, age, fatigue, fatigue on exertion, physical activity, functional class, drug therapy, dyspnea, body mass index, and smoking habits. METHODS: A cross sectional study, with a non-probability sample of 400 outpatients (mean age 57.8 years $(S D=11.6), 64.8 \%$ men, mean schooling $=6.1$ years $(\mathrm{SD}=3.9) ; 82.5 \%$ in functional class II or III) under treatment of $\mathrm{HF}$ in an academic hospital. Data were collected by interviews in which participants answered a set of tools including: demographic and heart failure data; and assessment of the sleep pattern (PSQI Pittsburgh Sleep Quality Index), fatigue ( Dutch Fatigue Scale DUFS), fatigue on exertion (Dutch Exertion Fatigue Scale), physical activity (International Physical Activity Questionnaire), and data on dyspnea, smoking habits and drug treatment. Reliability coefficients of the tools in this study were adequate (PSQI $\alpha=0.73$; DUFS $\alpha=0.90$; DEFS $\alpha=0.92$ ). Nonparametric tests were applied to analyze the association of sleep patterns with selected variables, and a logistic regression model was adjusted to investigate predictors of poor sleepers. RESULTS: The mean PSQI total score was 8.70 (SD 4.39), the prevalence of poor sleepers (PSQI> 5) was $68.5 \%$ and $46.5 \%$ rated sleep as poor or very poor. Higher PSQI scores or poor sleeper category was associated with: female gender ( $p$ $=0.009)$, unemployement $(p=0.013)$, fatigue $(p=0.000)$, fatigue on exertion $(p=0.000)$, dyspnea $(p=0.000)$ and higher HF functional class $(p=0.000)$. Dyspnea (OR=3.23; $\mathrm{Cl} 95 \% 1.72$ to 6.07 ) and fatigue (OR=3.45; $\mathrm{Cl} 95 \%$ 1.82 to 6.49 ) were independently associated with the poor sleeper category. CONCLUSIONS: The proportion of poor sleepers among patients with HF is among the highest rates in chronic diseases. Dyspnea and fatigue, commom symptoms in this illness, increase significantly the likelihood of being a poor sleeper. Therefore, the sleep pattern of HF patients has to be routinely assessed.
\end{abstract}

Key-words: Nursing, Sleep, Heart Failure, Fatigue, Dyspnea 


\section{LISTA DE QUADROS}

Quadro 1 - Descrição dos estudos sobre sono e insuficiência cardíaca. São Paulo, 2010

Quadro 2 - Dados das teses/dissertações selecionadas sobre sono e insuficiência cardíaca. São Paulo, 2010.

\section{LISTA DE TABELAS}

Tabela 1 - Características da amostra (N=400). São Paulo - 2009

Tabela 2 - Estatística descritiva dos escores nos componentes do PSQI $(\mathrm{N}=400)$. São Paulo - 2009

Tabela 3 - Estatística descritiva e p-valor dos testes de associação entre escores totais no PSQI e variáveis sociodemográficas em pacientes com IC ( $=400)$. São Paulo, 2009

Tabela 4 - Estatística descritiva e p-valor dos testes de associação entre escores totais no PSQI e variáveis clínicas em pacientes com IC $(\mathrm{N}=400)$. São Paulo, 2009

Tabela 5 - Estatística descritiva e p-valor dos testes de associação entre categorias de dormidores e variáveis sociodemográficas de pacientes com IC (N=400). São Paulo, 2009.

Tabela 6 - Estatística descritiva e p-valor dos testes de associação entre categorias de dormidores e variáveis clínicas de pacientes com IC $(\mathrm{N}=400)$. São Paulo, 2009 .

Tabela 7 - Principais resultados dos testes de associação entre as variáveis de sono e outras variáveis selecionadas. São Paulo, 2009.

Tabela 8 - Resultados da regressão logística para preditores de categoria de mau dormidor no PSQI. 


\section{SUMÁRIO}

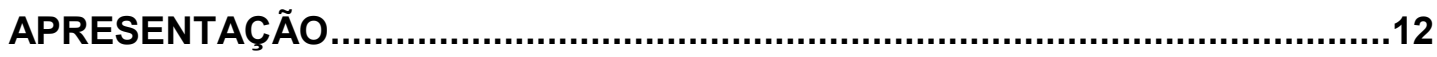

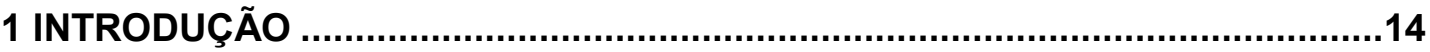

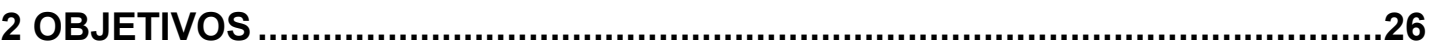

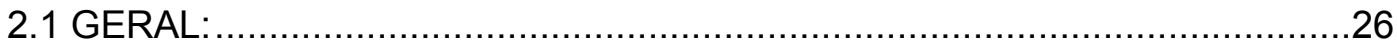

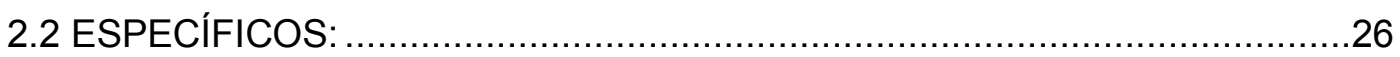

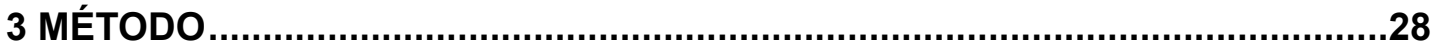

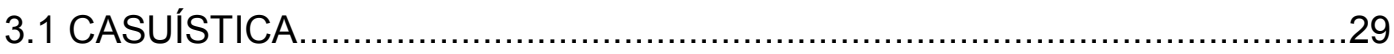

3.3.1 Critérios de inclusão e de exclusão..................................................29

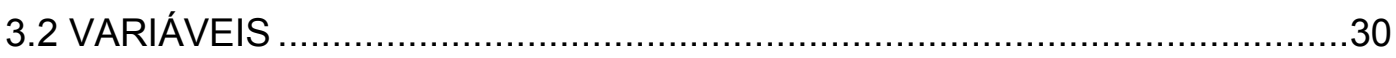

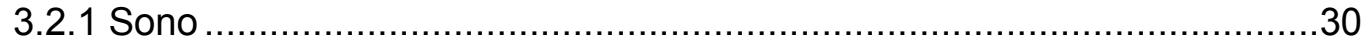

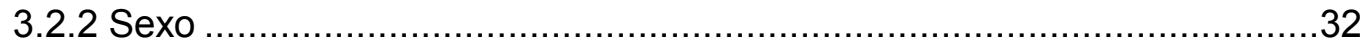

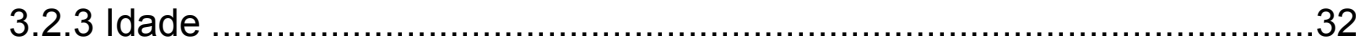

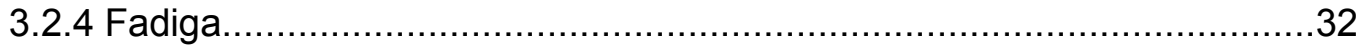

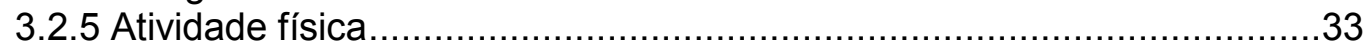

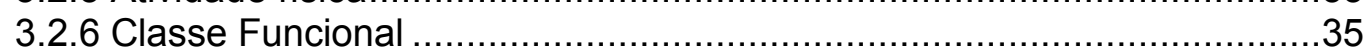

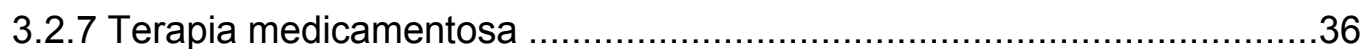

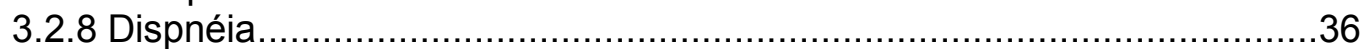

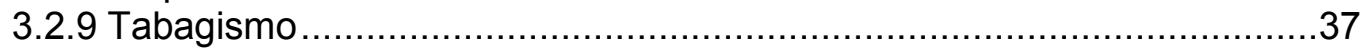

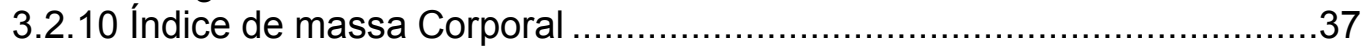

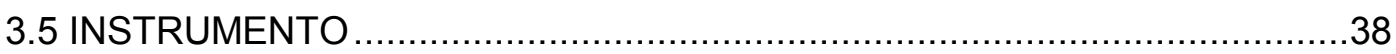

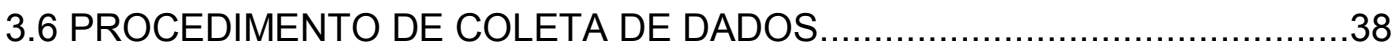

3.7 ANÁLISE ESTATÍSTICA DOS DADOS ................................................40

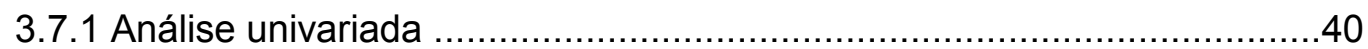

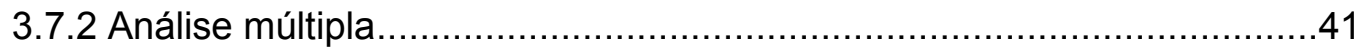

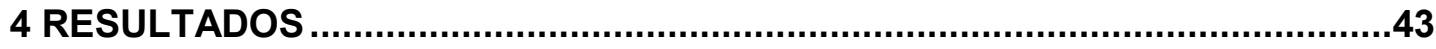

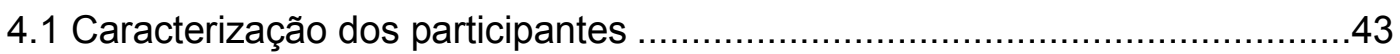

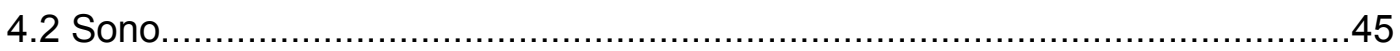

4.3 Associação entre sono e variáveis selecionadas .......................................46

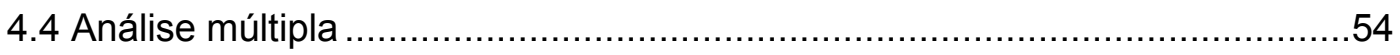

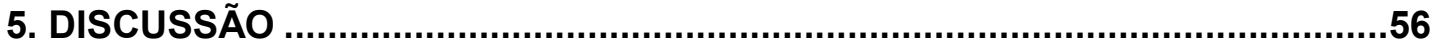

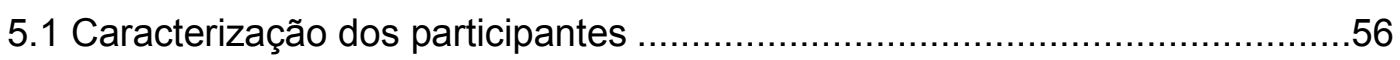

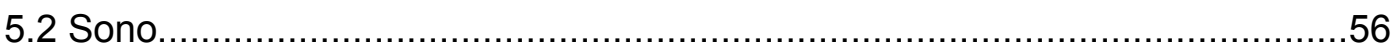

6 CONCLUSÕES

7 IMPLICAÇÕES E LIMITAÇÕES DO ESTUDO ..............................................72

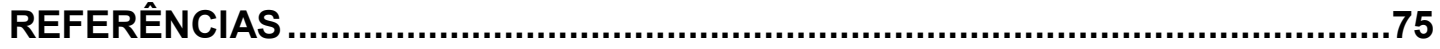

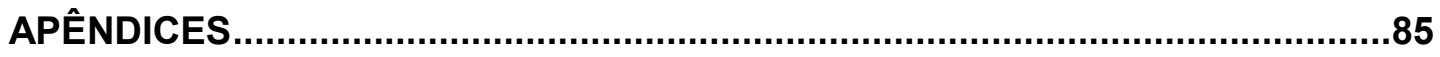

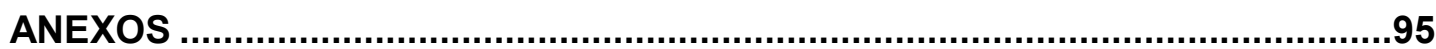


Apresentação 


\section{APRESENTAÇÃO}

O foco de atenção da enfermagem são as respostas que as pessoas apresentam aos problemas de saúde. Sendo assim, o conhecimento dessas respostas é importante para a disciplina de enfermagem.

Os pacientes com Insuficiência Cardíaca (IC) apresentam inúmeras respostas à sua condição primária que se expressam em várias esferas da experiência humana. Os diagnósticos de enfermagem referentes ao sono são comuns em pacientes de IC (Rausch et al., 2007; Chen, 2007; Redeker, 2008). Estudos recentes ressaltam a importância dos distúrbios do sono com os processos fisiopatológicos associados com o desenvolvimento da IC, a diminuição da qualidade de vida e do desempenho funcional (Redeker, 2008).

A proposta deste trabalho foi estudar o padrão de sono em pacientes com insuficiência cardíaca, considerando que o distúrbio do padrão de sono é um dos diagnósticos de enfermagem aceitos pela NANDA-International (Nanda, 2010) e que não foram encontrados estudos sobre essa resposta em amostra de população brasileira. 


\section{Introdução}




\section{INTRODUÇÃO}

Os avanços tecnológicos e a melhora das condições socioeconômicas têm propiciado aumento na expectativa de vida o que, por sua vez, tem favorecido o aumento das doenças crônico-degenerativas. Dentre elas destacam-se as do sistema cardiovascular que têm maior incidência nas faixas etárias mais avançadas (Zaslavsky, Gus, 2002). Entre as doenças crônico-degenerativas, destaca-se a insuficiência cardíaca que pertence ao grupo das doenças cardiovasculares e será o foco deste estudo.

A Insuficiência cardíaca (IC) é a via final comum da maioria das doenças que acometem o coração, sendo um dos mais importantes desafios clínicos atuais na área da saúde. É uma síndrome complexa de caráter sistêmico, definida como disfunção cardíaca que ocasiona inadequado suprimento sanguíneo para atender necessidades metabólicas tissulares (Sociedade Brasileira de Cardiologia, 2009); é uma doença complexa resultante de alteração estrutural e/ou funcional cardíaca, que prejudica a capacidade dos ventrículos de se encherem ou ejetarem sangue (Braunwald, 1999; Bacal, Silva, 2007). É a mais comum e cara doença crônica entre os idosos em países em desenvolvimento (Lloyd-Jones et al., 2009). A IC constitui hoje um dos maiores problemas de saúde pública em todo o mundo, trata-se de um problema em progressão.

Sua prevalência é estimada em 2,3\% na população geral e $0,4 \%$ a $2 \%$ na população européia; cerca de 5 milhões de pessoas nos EUA têm IC e a condição resulta em cerca de 300.000 mortes todo ano (Remme, Swedberg, 2001; Albanesi Filho, 2005). Segundo as diretrizes da Sociedade Brasileira de Cardiologia (2009), a IC apresenta um aumento na sua incidência no Brasil e no mundo. Os índices de hospitalização por IC dobraram nas duas últimas décadas. No ano de 2007, as doenças cardiovasculares representaram a terceira causa de internações no Sistema Único de Saúde (SUS), com 1.156.136 hospitalizações. A IC é a causa mais freqüente de internação por doença cardiovascular. 
Em 2007, a IC foi responsável por 2,6\% das hospitalizações e por $6,3 \%$ dos óbitos registrados pelo SUS-MS no Brasil, consumindo $3 \%$ do total de recursos utilizados para atender todas as internações realizadas pelo Sistema (Sociedade Brasileira de Cardiologia, 2009). É possível que os progressos na terapia médica e cirúrgica da IC, bem como o envelhecimento populacional, tenham contribuído para aumentar a taxa de internação nos casos mais avançados da doença, os quais ainda podem ser agravados pela coexistência de outras doenças crônicas.

O serviço de saúde suplementar no Brasil vem se expandindo e hoje 1 em cada 5 brasileiros é por ele atendido (Sociedade Brasileira de Cardiologia, 2009). Os dados sobre atendimentos ambulatoriais e hospitalares por IC neste cenário não estão disponíveis.

No Brasil, a principal etiologia da IC é a cardiopatia isquêmica crônica associada à hipertensão arterial. Em determinadas regiões geográficas do país e em áreas de baixas condições sócio-econômicas, ainda existem formas de IC associadas à doença de Chagas, endomiocardiofibrose e a cardiopatia valvular reumática crônica (Sociedade Brasileira de Cardiologia, 2009).

Esses dados refletem a relevância da IC não apenas como doença e suas conseqüências clínicas, mas como preocupante questão de ordem sócio-econômica quando se posiciona como uma das principais motivadoras de internação hospitalar e absenteísmo.

O diagnóstico da doença é clínico, laboratorial e por imagem. A avaliação clínica dará conta de buscar os sinais e sintomas, antecedentes patológicos e fatores predisponentes; os dados laboratoriais irão identificar a gravidade e outras condições clínicas associadas, e os exames por imagem trarão dados anatômicos e funcionais do coração. Na maioria das formas de IC, a redução do débito cardíaco é responsável pela inapropriada perfusão tecidual. De início este comprometimento do débito cardíaco se manifesta durante o exercício, e com a progressão da doença ele diminui no esforço até ser observado sua redução no repouso (Sociedade Brasileira de 
Cardiologia, 2009). Os sintomas do paciente com IC incluem a dispnéia e a fadiga, predominantemente durante o exercício. Outros sintomas possíveis são a dispnéia paroxística noturna, a ortopnéia, o edema de membros inferiores e a tosse noturna (Braunwald, 1999).

A IC crônica tem sido classicamente categorizada com base na intensidade de sintomas em 4 classes propostas pela New York Heart Association (NYHA) em 1964 e utilizadas até a atualidade (Braunwald, 1999; Sociedade Brasileira de Cardiologia, 2009). Essas classes estratificam o grau de limitação imposto pela doença para atividades cotidianas do indivíduo; vale dizer, portanto, que essa classificação além de possuir caráter funcional, é também uma maneira de avaliar a qualidade de vida do paciente frente a sua doença. As quatro classes propostas são:

Classe I: ausência de sintomas (dispnéia) durante atividades cotidianas. A limitação para esforços é semelhante à esperada em indivíduos normais;

Classe II: sintomas desencadeados por atividades cotidianas;

Classe III: sintomas desencadeados em atividades menos intensas que as cotidianas ou pequenos esforços;

Classe IV: sintomas em repouso.

Vale notar que essa categorização tem como base de referência para sua gradação as atividades cotidianas, que são variáveis de um indivíduo para outro, o que confere subjetividade a essa medida. Além do valor prognóstico da classe funcional aferida em avaliação inicial de pacientes, sua determinação serve para avaliar resposta terapêutica e contribuir para a determinação do melhor momento para intervenções (Sociedade Brasileira de Cardiologia, 2009).

A limitação funcional pode acarretar comprometimentos de ordem psicológica e social, com perdas na qualidade de vida. As atividades diárias serão dificultadas pelas repercussões físicas provocadas pela doença e seu tratamento. 
O tratamento da IC é farmacológico e não farmacológico. A abordagem farmacológica utilizada atualmente são os inibidores da enzima conversora de angiotensina (ECA), digitálicos e beta bloqueadores (Sociedade Brasileira de Cardiologia, 2009). As medidas não farmacológicas dizem respeito à mudança no estilo de vida, especialmente em relação a dieta e atividade física (Sociedade Brasileira de Cardiologia, 2009).

A IC têm diferentes impactos na qualidade de vida dos pacientes, mesmo que estejam sob tratamento. Mudanças na identidade, na função social e na capacidade física são experiências comuns em pacientes com IC (Joahansson et al., 2006; Santos et al., 2009), o que influencia diretamente o desempenho de suas atividades diárias (Joahansson et al., 2006; Manochia et al., 2001). A falta de cura e o prognóstico ruim da doença têm sido de progressivo interesse na pesquisa sobre a qualidade de vida desses pacientes.

A cronicidade da IC faz com que o paciente conviva e se submeta ao tratamento de uma doença para a qual não se obterá cura, não ficará isento do seu agravamento e ainda poderá não estar completamente livre da sintomatologia que trará prejuízos à sua qualidade de vida (Joahansson et al., 2006; Fini, 2008).

Esses prejuízos na qualidade de vida são decorrentes de vários fatores, especialmente de sintomas próprios da IC. Freqüentemente, esses pacientes têm suas funções limitadas pela dispnéia e fadiga, sintomas de pior evolução com o avançar da doença (Guimarães et al., 1999; Ekman et al., 2005).

As alterações do sono têm sido descritas como freqüentes e comuns entre os pacientes com IC. Estudos em populações com afecções cardiovasculares sugerem que o sono pobre influencia na qualidade de vida (Manochia et al., 2001; Bronstrom et al., 2001; Redeker, Hilkert, 2005; Phillips, 2005; Riegel, Weaver, 2009), além de ser um dos sintomas de mais incômodo para essa população (Zambroski et al., 2005). Pessoas com IC apresentam a quantidade e a qualidade do sono significantemente menor do 
que pessoas sem IC (Riegel, Weaver, 2009). O sono de má qualidade pode ser suficiente para comprometer a cognição a ponto de interferir nas práticas de auto-cuidado. Sendo assim, o sono inadequado pode contribuir para qualidade de vida prejudicada por relatos de saúde ruim e maior risco de hospitalização não planejada.

Os distúrbios de sono podem estar associados com outras variáveis próprias do paciente com IC. Sabe-se, por exemplo, que os distúrbios respiratórios relatados durante o sono, incluindo a respiração Cheyne-Stokes com apnéia central e a apnéia obstrutiva do sono afetam a função cardíaca dos pacientes com IC (Phillips, 2005; Chen et al., 2007); que o estresse psicológico e ansiedade, causados pela progressão da doença, podem afetar o sono, bem como a fadiga física e mental, freqüentes entre os pacientes com IC (Redeker, Hilkert, 2005). Há ainda de se considerar os prejuízos econômicos que a restrição/prejuízo do sono traz à sociedade (Colten, Altevogt, 2006).

Considerando que o sono é importante para a manutenção da qualidade de vida e que, nos pacientes com IC ele está prejudicado, este estudo teve como tema central o sono em pacientes com insuficiência cardíaca.

Em busca bibliográfica realizada em abril de 2010 no PubMed utilizando o MESH como "major topic" com os descritores "SLEEP" e "HEART FAILURE" ("Heart Failure"[Majr] AND "Sleep"[Majr]) foram localizadas 27 referências. A análise dos títulos e resumos mostrou que apenas 13 eram de pesquisas sobre características objetivas ou subjetivas do sono em pacientes com IC, permitindo explorar as variáveis potencialmente associadas aos distúrbios do sono.

O conteúdo dessas publicações está sintetizado no Quadro 1. 
Quadro 1 - Descrição dos estudos sobre sono e insuficiência cardíaca. São Paulo, 2010.

\begin{tabular}{|c|c|c|c|}
\hline Autor/Ano & Objetivo & Método & Principais resultados \\
\hline Soll, 2009 & $\begin{array}{l}\text { Avaliar a resposta } \\
\text { hemodinâmica e } \\
\text { respiratória ao ângulo do } \\
\text { sono em pacientes com } \\
\text { IC estável }\end{array}$ & $\begin{array}{l}\text { - } 25 \text { pacientes } \\
\text { - polissonografia } \\
\text { - Eletrocardiograma } \\
\text { - variação do ângulo para } \\
\text { dormir: } 0,15,30 \text { e } 45 \text { graus }\end{array}$ & $\begin{array}{l}\text { A mudança do ângulo de } \\
\text { dormir resulta numa } \\
\text { diminuição significativa } \\
\text { nas apnéias de Cheyne- } \\
\text { Stokes, porém não estão } \\
\text { relacionadas com } \\
\text { mudanças } \\
\text { hemodinâmicas. }\end{array}$ \\
\hline Yeh,2008 & $\begin{array}{l}\text { Analisar os efeitos de um } \\
\text { programa de exercícios } \\
\text { Tai Chi no estado do } \\
\text { sono em pacientes com } \\
\text { IC }\end{array}$ & $\begin{array}{l}\text { - } 18 \text { pacientes } \\
\text { - análise retrospectiva de grupo } \\
\text { experimental e controle } \\
\text { - Eletrocardiograma } 24 \mathrm{~h} \\
\text { - ETST (percentagem da } \\
\text { estimativa do tempo total do } \\
\text { sono) }\end{array}$ & $\begin{array}{l}\text { Exercícios de Tai Chi } \\
\text { melhoram o sono de } \\
\text { pacientes com IC. }\end{array}$ \\
\hline Zilberman,2007 & $\begin{array}{l}\text { Analisar se a correção } \\
\text { da anemia melhora os } \\
\text { distúrbios respiratórios } \\
\text { de sono em pacientes } \\
\text { com IC }\end{array}$ & $\begin{array}{l}\text { - } 38 \text { pacientes } \\
\text { - estudo transversal } \\
\text { - tratamento com eritropoietina } \\
\text { e questionário para avaliação } \\
\text { da sonolência diurna (Epworth } \\
\text { Sleepiness Scale) durante os } 3 \\
\text { meses do tratamento }\end{array}$ & $\begin{array}{l}\text { Melhora/correção da } \\
\text { anemia está associada } \\
\text { com redução dos } \\
\text { distúrbios respiratórios de } \\
\text { sono e melhora da } \\
\text { sonolência diurna. }\end{array}$ \\
\hline Redeker,2006 & $\begin{array}{l}\text { Analisar as } \\
\text { características do sono } \\
\text { em pacientes com e sem } \\
\text { IC }\end{array}$ & $\begin{array}{l}\text { - estudo caso controle } \\
\text { - } 59 \text { pacientes em cada grupo } \\
\text { - PSQI - Pittsburgh Sleep } \\
\text { Quality Index (instrumento de } \\
\text { auto-avaliação do sono) } \\
\text { - Epworth Sleep Scale (para } \\
\text { avaliar sonolência) }\end{array}$ & $\begin{array}{l}\text { Pacientes com IC tiveram } \\
\text { pior qualidade de sono } \\
\text { que pacientes sem IC } \\
\text { ( } p=0,017) \\
\text { Em } 4 \text { dos } 7 \text { componentes } \\
\text { do PSQI os pacientes com } \\
\text { IC tiveram piores escores } \\
\text { que os controles. }\end{array}$ \\
\hline Redeker, 2005 & $\begin{array}{l}\text { Analisar a associação da } \\
\text { qualidade, duração e } \\
\text { evolução do sono com } \\
\text { desempenho funcional e } \\
\text { mental de pacientes com } \\
\text { IC estável }\end{array}$ & $\begin{array}{l}\text { - } 61 \text { pacientes } \\
\text { - estudo descritivo, transversal } \\
\text { - Actígrafo de pulso para } \\
\text { avaliar duração e continuidade } \\
\text { do sono } \\
\text { - PSQI (Pittsburg Sleep Quality } \\
\text { Index) } \\
\text { - SF } 36 \text { - Health Survey ( } \\
\text { estado emocional/mental) }\end{array}$ & $\begin{array}{l}\text { Continuidade e qualidade } \\
\text { do sono são associadas } \\
\text { com o desempenho } \\
\text { funcional e com a saúde } \\
\text { mental independente de } \\
\text { sexo, idade e } \\
\text { comorbidades. }\end{array}$ \\
\hline Skobel, 2005 & $\begin{array}{l}\text {-Avaliar sono e seus } \\
\text { efeitos na qualidade de } \\
\text { vida de pacientes com IC }\end{array}$ & $\begin{array}{l}\text { - } 69 \text { pacientes } \\
\text { - observados por } 8 \text { meses } \\
\text { - Polissonografia } \\
\text { - BDI (Beck Depression } \\
\text { Inventory) } \\
\text { - PSQI (Pittsburg Sleep Quality } \\
\text { Index) } \\
\text { - SF } 36 \text { Health Survey }\end{array}$ & $\begin{array}{l}\text { Há associação entre pior } \\
\text { qualidade de sono e } \\
\text { depressão. } \\
\text { PSQI: } 37 \% \text { eram maus } \\
\text { dormidores. }\end{array}$ \\
\hline Yamazaki,2005 & $\begin{array}{l}\text { Examinar se a inibição } \\
\text { simpática central } \\
\text { melhora a qualidade do } \\
\text { sono em pacientes com } \\
\text { IC }\end{array}$ & $\begin{array}{l}\text {-Eletrocardiograma durante o } \\
\text { sono } \\
\text { - } 14 \text { pacientes e } 13 \text { controles } \\
\text { - administração de um agonista } \\
\text { adrenérgico (guanfacine) e } \\
\text { análise da relação das fases } \\
\text { REM / não REM do sono }\end{array}$ & $\begin{array}{l}\text { Inibição simpática central } \\
\text { melhora ritmo circadiano } \\
\text { sugerindo benefício na } \\
\text { qualidade de sono em } \\
\text { pacientes com IC crônica. }\end{array}$ \\
\hline
\end{tabular}




\begin{tabular}{|c|c|c|c|}
\hline Brostrom,2003 & $\begin{array}{l}\text { Descrever situações que } \\
\text { influenciam na qualidade } \\
\text { de sono de pacientes } \\
\text { com IC }\end{array}$ & $\begin{array}{l}\text { - estudo qualitativo } \\
\text {-25 pacientes } \\
\text { - Entrevista por especialista }\end{array}$ & $\begin{array}{l}\text { Ansiedade, limitações } \\
\text { respiratórias e micção } \\
\text { noturna são fatores que } \\
\text { influenciam na qualidade } \\
\text { de sono. }\end{array}$ \\
\hline Krachman,1999 & $\begin{array}{l}\text { Comparar os efeitos da } \\
\text { terapia com oxigênio e } \\
\text { terapia com Continuous } \\
\text { positive airway pressure } \\
\text { (CPAP) na IC }\end{array}$ & $\begin{array}{l}\text { - estudo prospectivo, } \\
\text { randomizado } \\
\text { - } 25 \text { pacientes em cada grupo } \\
\text { - questionário de sono, nível de } \\
\text { saturação de oxigênio e } \\
\text { Eletroencefalograma } \\
\text {-oxigenioterapia e Continuous } \\
\text { positive airway pressure } \\
\text { (CPAP) }\end{array}$ & $\begin{array}{l}\text { Não houve diferença } \\
\text { significativa entre as } 2 \\
\text { modalidades. }\end{array}$ \\
\hline Staniforth, 1998 & $\begin{array}{l}\text { Avaliar os efeitos da } \\
\text { terapia com oxigênio na } \\
\text { qualidade de sono em } \\
\text { pacientes com IC }\end{array}$ & $\begin{array}{l}\text { - estudo cross-over, duplo- } \\
\text { cego } \\
\text {-11 pacientes com respiração } \\
\text { Cheyne-Stokes } \\
\text { - polissonografia } \\
\text {-Epworth Sleepiness Scale }\end{array}$ & $\begin{array}{l}97 \% \text { tinham apnéia de } \\
\text { origem central } \\
\text { Terapia com oxigêncio } \\
\text { reduziu tempo de apnéia. }\end{array}$ \\
\hline Hanly, 1996 & $\begin{array}{l}\text { Avaliar a síndrome das } \\
\text { pernas inquietas e seus } \\
\text { efeitos no sono de } \\
\text { pacientes com IC }\end{array}$ & $\begin{array}{l}\text { - } 23 \text { pacientes e } 9 \text { controles } \\
\text { - polissonografia } \\
\text { - Epworth Sleepiness Scale } \\
\text { - Multiple Sleep Latency Test } \\
\text { (MSLT) }\end{array}$ & $\begin{array}{l}\text { Síndrome é alta em } \\
\text { pacientes com IC (52\%), é } \\
\text { maior que nos controles } \\
\text { (11\%); maior intensidade } \\
\text { da síndrome está } \\
\text { associada com pior } \\
\text { qualidade do sono. }\end{array}$ \\
\hline Hanly, 1995 & $\begin{array}{l}\text { Determinar se pacientes } \\
\text { com IC que desenvolvem } \\
\text { Cheyne Stokes durante } \\
\text { o sono têm sonolência } \\
\text { excessiva diária }\end{array}$ & $\begin{array}{l}\text { - } 3 \text { grupos } \\
\text { - estudo transversal } \\
\text { - } 7 \text { pacientes com IC e Cheyne } \\
\text { Stokes; } 7 \text { com IC e sem } \\
\text { Cheyne Stokes; } 9 \text { controles } \\
\text { - polissonografia } \\
\text { - Escala para avaliar } \\
\text { sonolência durante o dia }\end{array}$ & $\begin{array}{l}\text { Pacientes com IC e } \\
\text { Cheyne Stokes têm piores } \\
\text { indicadores de sono que } \\
\text { pacientes com IC sem } \\
\text { Cheyne Stokes. }\end{array}$ \\
\hline Steens, 1994 & $\begin{array}{l}\text { Documentar os efeitos } \\
\text { da inalação de CO2 no } \\
\text { Cheyne-Stokes em } \\
\text { pacientes com } \\
\text { insuficiência cardíaca } \\
\text { estável }\end{array}$ & $\begin{array}{l}\text {-6 pacientes } \\
\text { - polissonografia por } 3 \text { noites } \\
\text {-inalação controlada de dióxido } \\
\text { de carbono }\left(\mathrm{CO}_{2}\right)\end{array}$ & $\begin{array}{l}\text { Inalação controlada de } \\
\text { dióxido de carbono }\left(\mathrm{CO}_{2}\right) \\
\text { erradica o Cheyne-Stokes } \\
\text { durante a polissonografia } \\
\text { em pacientes com IC } \\
\text { estável. }\end{array}$ \\
\hline
\end{tabular}

Os estudos no Quadro 1 tratam predominantemente de análises de qualidade/padrão de sono em pacientes com insuficiência cardíaca utilizando diferentes formas de mensuração. Associação do sono com outras variáveis como: depressão (Skobel et al., 2005), ansiedade (Bronstrom et al., 2003), distúrbios respiratórios (Krachman et al., 1999; Staniforth et al., 1998; Hanly, Zuberi-Khokhar, 1995; Steens et al., 1994) estão presentes; bem como alguns estudos de intervenção (Yeh et al., 2008; Yamazaki et al., 2005). 
Em busca realizada em abril de 2010, no Banco de Teses da Capes, com os descritores "SONO" E "INSUFICIÊNCIA CARDÍACA", foram encontradas 25 teses/dissertações e somente 4 atendiam a proposta desta revisão (Quadro 2). Os estudos excluídos tratavam na sua maioria de comparação de testes específicos para avaliação respiratória durante o sono e estudos experimentais em outras populações.

Quadro 2 - Dados das teses/dissertações selecionadas sobre sono e insuficiência cardíaca. São Paulo, 2010.

\begin{tabular}{|c|c|c|c|}
\hline Autor/Ano & Objetivos & Método & Principais resultados \\
\hline Fini, 2008 & $\begin{array}{l}\text { Caracterizar a fadiga em } \\
\text { pacientes com IC e } \\
\text { comparar sua freqüência } \\
\text { e intensidade em } \\
\text { voluntários sem a doença }\end{array}$ & $\begin{array}{l}\text { - estudo descritivo- } \\
\text { exploratório } \\
\text { - } 300 \text { pacientes } \\
\text { ambulatoriais e } 64 \\
\text { voluntários sem a doença } \\
\text { - Instrumentos com escalas } \\
\text { de medida de fadiga, } \\
\text { depressão,atividade física } \\
\text { e outros itens. }\end{array}$ & $\begin{array}{l}\text { Houve associação entre } \\
\text { fadiga ao esforço e } \\
\text { distúrbios do sono. }\end{array}$ \\
\hline Sá,2006 & $\begin{array}{l}\text { Estudar o sono, } \\
\text { quantificar os valores } \\
\text { espirométricos e avaliar a } \\
\text { força da musculatura } \\
\text { respiratória dos pacientes } \\
\text { com IC }\end{array}$ & $\begin{array}{l}\text { - estudo transversal } \\
\text { - } 13 \text { pacientes com IC } \\
\text { - Polissonografia } \\
\text { - Espirometria } \\
\text { - Manovacuometria }\end{array}$ & $\begin{array}{l}84,6 \% \text { apresentaram } \\
\text { apnéia obstrutiva central } \\
\text { Não houve correlação } \\
\text { entre as variáveis } \\
\text { estudadas. }\end{array}$ \\
\hline Uchiyama,2005 & $\begin{array}{l}\text { Estudar a desaturação da } \\
\text { oxihemoglobina durante o } \\
\text { sono em pacientes com } \\
\text { IC }\end{array}$ & $\begin{array}{l}\text { - estudo transversal } \\
\text { - } 15 \text { pacientes } \\
\text { - oximetria digital noturna } \\
\text { - Índice de Massa Corporal } \\
\text { (IMC) }\end{array}$ & $\begin{array}{l}\text { - Quanto maior o IMC e a } \\
\text { idade, maior o prejuízo } \\
\text { na saturação de } \mathrm{O}_{2} \\
\text { durante o sono. }\end{array}$ \\
\hline Silva,2004 & $\begin{array}{l}\text { Determinar prevalência de } \\
\text { distúrbios respiratórios do } \\
\text { sono em pacientes } \\
\text { ambulatoriais com IC. }\end{array}$ & $\begin{array}{l}\text { - estudo transversal } \\
\text { - } 89 \text { pacientes } \\
\text { - polissonografia }\end{array}$ & $\begin{array}{l}56 \% \text { dos pacientes } \\
\text { apresentaram distúrbios } \\
\text { respiratórios do sono } \\
\text { (46\% respiração Cheyne- } \\
\text { Stokes e } 10 \% \text { apnéia } \\
\text { obstrutiva) } \\
\text { Os distúrbios } \\
\text { respiratórios do sono não } \\
\text { se associaram a pior } \\
\text { prognóstico. } \\
\text { Os homens } \\
\text { apresentaram distúrbios } \\
\text { respiratórios do sono } \\
\text { mais graves e pior } \\
\text { qualidade de sono do que } \\
\text { as mulheres. }\end{array}$ \\
\hline
\end{tabular}


Dos estudos das teses e dissertações, podem-se destacar as seguintes variáveis associadas ao sono: distúrbios respiratórios (Sá, 2006; Silva, 2004), índice de massa corporal e idade (Uchiyma, 2005), e sexo (Silva, 2004).

A procura no LILACS, com os mesmos descritores de assunto, trouxe 9 estudos, que não foram considerados relevantes para esta revisão: distúrbios respiratórios associados a IC (como apnéia, asma, cheynestokes), monitorização da pressão arterial e analgesia na IC.

Os estudos analisados mostram que alguns sintomas da IC estão entre os fatores associados aos distúrbios do sono (Redeker, Stein, 2006). E por isso é importante considerá-los nos estudos sobre o sono e IC.

A fadiga é uma das manifestações freqüentes na IC, além de ser significativamente relacionada com a evolução desfavorável da doença (Ekman et al., 2005). Estudo recente realizado com pacientes com IC mostrou que o distúrbio do sono foi estatisticamente associado a todas as variáveis de fadiga, sendo que intensidades de fadiga e de fadiga ao esforço foram mais altas entre os pacientes com distúrbio do sono (Fini, 2008). Assim como a fadiga, a dispnéia é um sintoma comum na IC (Skobel et al., 2005) e chega a ser apontada, pelos pacientes, como a própria causa da fadiga (Ramasamy et al., 2006; Riegel, Weaver, 2009).

Pacientes com IC, freqüentemente, têm a atividade física limitada pela dispnéia e fadiga, mesmo quando assintomáticos em repouso. Conseqüentemente, esses pacientes, quando comparados a pessoas sem IC, apresentam baixa tolerância ao exercício físico e acentuadas respostas metabólicas e respiratórias para a mesma intensidade de trabalho (Bronstrom et al., 2004; Uren, Lipkin, 1992). Porém, encontrou-se apenas um estudo com amostras de pacientes com IC que sugere associação entre atividade física e sono, ao mostrar que a prática de Tai Chi Chuan melhora a qualidade do sono (Yeh et al., 2008). Sendo assim, estudos de associação 
Mariana Alvina dos Santos

entre atividade física e sono seriam de grande importância para proposta de melhora na qualidade de vida desses pacientes.

Além dos sintomas da doença, há associação das alterações do sono com outros fatores que têm sido estudados nos pacientes com IC, como por exemplo: sexo, idade e outras variáveis clínicas (Redeker, Hilkert, 2005; Silva, 2004; Bronstrom et al., 2004; Riegel, Weaver, 2009; Sá, 2006; Uren, Lipkin, 1992; Uchiyma, 2005).

Quanto às variáveis clínicas, o grau de agravamento da IC deve ser considerado no estudo do sono, pois admite-se que a qualidade do sono seja pior em classes funcionais mais elevadas (Príncipe-Rodriguez et al., 2005). Outro fator a ser considerado é a saturação de $\mathrm{O}_{2}$ durante o sono (Uchiyama, 2005), que aparentemente está associado aos distúrbios respiratórios que acompanham a IC como, por exemplo, a apnéia central do sono, ou respiração Cheyne-Stokes (Uren, Lipkin, 1992; Hanly, ZuberiKhokhar, 1995; Sá, 2006; Ramasamy et al., 2006).

A terapia medicamentosa tradicional, baseada no uso de digital e diurético, permite obter melhora na função cardíaca e sintomatologia (Uren, Lipkin, 1992; Riegger et al., 1999). No entanto, o regime terapêutico comumente usado na IC pode contribuir para um sono de má qualidade (Qureshi, Lee- Chiong, 2004). Há relato de que o uso de algumas classes de beta-bloqueadores tem efeitos piores nas características do sono (Yilmaz et al., 2008), possivelmente por provocarem diminuição na produção noturna de melatonina (Zisapel, 2007).

Os transtornos do sono consistem em uma das principais sintomatologias do transtorno depressivo e o humor depressivo é freqüente na IC (Freedland, Carney, 2000; Chellapa, Araújo, 2007; Leetge-Lesman et al., 2008). Diversos estudos sobre as alterações dos padrões do sono têm auxiliado sobremaneira na compreensão dos mecanismos neurobiológicos da desregulação do humor no transtorno depressivo. Um total de $80 \%$ dos pacientes com depressão apresenta alterações tanto na quantidade como da qualidade do sono, com queixas freqüentes de insônia, havendo dificuldade 
de iniciar e manter o sono (Chellapa, Araújo, 2006). Como a depressão e sono são associados em diferentes amostras, é importante estudar a associação entre essas variáveis nos pacientes com IC.

Os distúrbios respiratórios têm importante papel na qualidade do sono também em outras populações que não os pacientes com IC. Episódios recorrentes de obstrução total (apnéia) ou parcial (hipopnéia) da via aérea superior durante o sono ocorrem principalmente em indivíduos obesos. $O$ progressivo aumento da prevalência do sobrepeso e obesidade na população contribui para maior prevalência dos distúrbios do sono em população geral (Sousa et al., 2008). Assim, o peso corporal é uma variável importante nos estudos de sono entre os pacientes com IC.

Doença de impacto pessoal, familiar, social e econômico, a IC ocupará espaço ainda maior num futuro próximo. $O$ aumento da perspectiva/qualidade de vida dos pacientes portadores dessa doença crônica requer estudos que descrevam os sintomas ou fatores a ela associados, nos quais possam ser pautadas propostas de intervenções para reduzi-los. 


\section{Objetivos}




\section{OBJETIVOS}

Considerando a importância do sono na qualidade de vida das pessoas; que na IC os problemas de sono podem estar associados a outros sintomas e que não se localizaram pesquisas sobre sono em amostras de brasileiros com IC, este estudo tem os seguintes objetivos:

\subsection{GERAL:}

Descrever o padrão de sono em pacientes portadores de IC.

\subsection{ESPECÍFICOS:}

Analisar associações entre padrão de sono com as seguintes variáveis: sexo, idade, fadiga, fadiga ao esforço, atividade física, classe funcional, terapia medicamentosa, dispnéia e índice de massa corporal.

Investigar a contribuição de variáveis sociais e clínicas (sexo, idade, fadiga, fadiga ao esforço, atividade física, classe funcional, terapia medicamentosa, dispnéia e índice de massa corporal) para a qualidade do sono. 
Método 


\section{MÉTODO}

Este foi um estudo transversal, descritivo, realizado no ambulatório de insuficiência cardíaca do Instituto Dante Pazzanese de Cardiologia, uma autarquia do Governo do Estado de São Paulo, associada à Universidade de São Paulo para fins de ensino, pesquisa e extensão. Trata-se de um hospital-escola especializado em cardiologia, localizado na cidade de São Paulo.

O Instituto Dante Pazzanese de Cardiologia foi fundado em 1954, possui atualmente 496 leitos e é tido como um dos maiores hospitais de cardiologia da América Latina.

O ambulatório pertence à Divisão Clínica e possui 100 salas para atendimento em diferentes especialidades cardiológicas: Coronariopatias, Miocardiopatias, Doença de Chagas, Trasnplante Cardíaco/CardioPulmonares, Hipertensão Arterial, Valvopatias, Cardiopatia e Gravidez, Cardiopatias Congênitas, Doenças Vasculares Periféricas, Cardiogeriatria, Cardiologia do Esporte, Angioplastia Coronária, Pós-operatório de Cirurgias Coronárias, Pós-operatório de Valvopatias, Pós-operatório de Cardiopatias Congênitas, Emergências Cardiovasculares, Arritmias Cardíacas, Eletrofisiologia, Marcapassos e Desfibriladores. Existem ainda outras especialidades médicas de apoio ao atendimento cardiológico como: Neurologia, Transplante Renal/Nefrologia, Pneumologia, Endocrinologia, Transplante Hepático, Ginecologia/Obstetrícia, Nutrologia e Anestesia.

A coleta de dados foi realizada em uma sub-unidade desse grande ambulatório, denominada ambulatório de insuficiência cardíaca, onde são atendidos pacientes com disfunções ventriculares multicausais e também aqueles em programa para transplante cardíaco. 


\subsection{CASUÍSTICA}

O estudo foi realizado com amostra, não probabilística, de 400 pacientes em acompanhamento clínico ambulatorial de insuficiência cardíaca.

O tamanho da amostra de pacientes para este estudo foi calculado com base em estimativas de prevalência de maus dormidores ( $P S Q I>5$ ) entre os pacientes com IC. Num estudo com 59 pacientes obteve-se prevalência de $67,8 \%$ (Redeker, Hilkert, 2005) de maus dormidores e em outro, com 125 pacientes, 74,4\% (Chen, et al., 2009). Há registros de prevalências mais baixas, mas, nesses casos foram usados outros pontos de corte, como 37\%, para escores no PSQI maiores que 10 (Skobel, et al., 2005) e 57,5\%, para escores maiores que 6 (Sayar, et al.,2002) .

Como a variação das prevalências na literatura foi grande, tomou-se como base de cálculo uma prevalência de $50 \%$, que resultou em maior tamanho de amostra, com precisão absoluta da estimativa igual a $5 \%$ e significância de 0.05 . O resultado foi de uma amostra igual a 384 pacientes. Foram incluídos 400 pacientes para cobrir eventuais perdas que, no final, não ocorreram.

\subsubsection{Critérios de inclusão e de exclusão}

Foram incluídos no estudo os pacientes em acompanhamento ambulatorial no serviço mencionado com os seguintes critérios:

- Estar em acompanhamento para o tratamento de insuficiência cardíaca;

- Ter no mínimo 18 anos de idade;

- Ter condições de compreender e responder os questionários. 
Foram excluídos pacientes portadores de doenças oncológicas, infecciosas com repercussão no estado geral, endócrinas (diabetes mellitus e tireoidianas sem tratamento). E também pacientes em pós-operatório recente (até 60 dias de pós operatório) de qualquer intervenção cirúrgica, bem como aqueles que já tinham sido submetidos ao transplante cardíaco.

\subsection{VARIÁVEIS}

As variáveis do estudo foram: sono, sexo, idade, fadiga, atividade física, classe funcional da IC, terapia medicamentosa, dispnéia e IMC.

A depressão era variável deste estudo, mas foi excluída por recomendação do Comitê de Ética. A proposta era aplicar o Inventário de Depressão de Beck (Gorestein, Andrade, 1996) para operacionalizar essa variável e o Comitê de Ética, ressaltando que a aplicação desse instrumento é exclusiva do profissional psicólogo, recomendou a revisão do projeto e optou-se, então, por excluir essa variável.

\subsubsection{Sono}

Essa variável foi avaliada pela aplicação do Pittsburg Sleep Quality Index-PSQI. O PSQI (Buysse et al., 1989), publicado em 1989 por Buysse, avalia a qualidade do sono no último mês. Esse é um período intermediário entre os questionários que avaliam somente a noite anterior, não sendo capazes de detectar padrões de disfunção, e aqueles que avaliam o último ano ou mais, não indicando a gravidade de um problema no momento da avaliação. Deve-se observar, como uma importante característica desse questionário, a combinação da informação quantitativa e qualitativa sobre o sono que ele fornece. 
O PSQI foi desenvolvido com o objetivo de fornecer uma medida válida, confiável, padronizada, fácil de ser respondida e interpretada para avaliação de qualidade de sono; discriminar os sujeitos avaliados entre bons e maus dormidores; e, além disso, que fosse clinicamente útil na avaliação de uma variedade de transtornos do sono que podem afetar a sua qualidade (Byusse et al., 1989).

O questionário consiste de 19 questões auto-administradas e 5 questões respondidas por companheiros de quarto de quem responde o instrumento. Essas últimas são utilizadas somente para informação clínica. As 19 questões são agrupadas em 7 componentes com pesos distribuídos numa escala de 0 a 3 . Esses componentes do PSQI são versões padronizadas de áreas rotineiramente avaliadas em entrevistas clínicas de pacientes com queixas em relação ao sono, e são: qualidade subjetiva do sono, latência do sono, duração do sono, eficiência habitual do sono, transtornos do sono, uso de medicamentos para dormir e disfunção diurna. As pontuações desses componentes são então somadas para produzir um escore global, que varia de 0 a 21, e quanto maior a pontuação, pior a qualidade do sono. Um escore global do PSQI > 5 indica que o indivíduo está apresentando grandes dificuldades em pelo menos 2 componentes, ou dificuldades moderadas em mais de 3 componentes. Como bons dormidores são categorizados os que obtém escores $\leq 5$ e como maus dormidores os com escores $\square$ que 5 (Buysse et al., 1989).

Desde sua elaboração, o PSQI tem sido amplamente utilizado para medir a qualidade de sono em diferentes grupos de pacientes, como portadores de doença renal crônica, transplantados renais, diabéticos, portadores de dor crônica, doença de Parkinson, doença inflamatória intestinal, asma e câncer (Sabattini et al., 2005; Costa et al., 2005; Ranjbaran et al., 2007; Yuksel et al., 2007; Mystakidou et al., 2007), além de naqueles com transtornos psiquiátricos ou do sono. Ele foi validado recentemente para uso no Brasil em estudo feito por BERTOLAZZI (Bertolazzi, 2008), que obteve boas estimativas de confiabilidade (alfa de Cronbach 0,82 ) e de validade (escores do PSQI para pacientes com apnéia 
obstrutiva do sono, depressão e insônia foram significativamente maiores que para controles).

A confiabilidade do PSQI na amostra deste estudo foi estimada pelo alfa de Cronbach sobre os escores dos 7 componentes, obtendo-se coeficiente de 0,73, o que pode ser considerado adequado (Pasquali, 2003). O alfa de Cronbach fornece um coeficiente geral que reflete o grau de covariância dos itens entre si, servindo assim de indicador da consistência interna do teste (Pasquali, 2003).

\subsubsection{Sexo}

A variável sexo foi indicada como feminino ou masculino, de acordo com a aparência do paciente observada pelo pesquisador, ou de acordo com a referência que o paciente fazia de si próprio. Foi tratada com qualitativa nominal.

\subsubsection{Idade}

A idade foi informada pelo paciente no dia da entrevista e considerada em duas categorias ( $<60$ anos ou $\geq 60$ anos - variável qualitativa nominal).

\subsubsection{Fadiga}

Essa variável foi avaliada pelas escalas Dutch Fatigue Scale - DUFS e Dutch Exertion Fatigue Scale - DEFS. Essas escalas foram desenvolvidas por três holandeses e publicadas em 1998 (Tiesinga et al., 1998). A DUFS mede fadiga definida como "uma sensação opressiva e sustentada de exaustão e de capacidade diminuída para realizar trabalho físico e mental no 
nível habitual". A DEFS mede fadiga ao esforço definida como a "fadiga que é diretamente relacionada à atividade" (Tiesinga et al., 1998).

O processo de adaptação para a língua portuguesa e validação das escalas foi realizado por FINI (Fini, 2008), com boas estimativas de confiabilidade em amostra de pacientes com IC (DUFS $=0,84$ e DEFS= $0,92)$.

A escala DUFS possui 8 itens. Os escores nos itens podem ser somados num escore total que varia de 8 a 40 (quanto mais alto o escore, maior a intensidade da fadiga). A DEFS, que mensura fadiga ao esforço, possui 9 itens, que podem ser somados num escore total que varia de 9 a 45 , indicando a intensidade da fadiga ao esforço (quanto maior o escore, maior a intensidade).

Para as análises estatísticas as variáveis fadiga e fadiga ao esforço foram tratadas como qualitativas nominais e também como quantitativas contínuas. Para tratá-las como qualitativas foram aplicados os pontos de corte obtidos no estudo de Fini (2008): para a DUFS $\geq 14,5$ foram classificados como casos de fadiga e para a DEFS os escores a $\geq 12,5$ como casos de fadiga ao esforço.

A confiabilidade da DUFS neste estudo foi de 0,90 pelo alfa de Cronbach e da DEFS foi de 0,92, mostrando adequada consistência interna (Pasquali, 2003) desses instrumentos neste estudo.

\subsubsection{Atividade física}

A avaliação da atividade física foi feita por meio da aplicação do IPAQ - International Physical Activity Questionnaire. Esse questionário foi proposto pela Organização Mundial de Saúde como um instrumento para determinar o nível de atividade física da população em âmbito mundial. Foi desenvolvido como parte de um estudo multicêntrico em 12 países. No Brasil, o IPAQ foi validado pelo Centro de Estudos do Laboratório de Aptidão 
Física de São Caetano do Sul (CELAFISCS) (Matsudo et al., 2001). A versão utilizada neste estudo foi a forma curta do questionário, que contém perguntas sobre a freqüência e duração da realização de atividades físicas moderadas, vigorosas e da caminhada na última semana.

As respostas ao IPAQ produzem uma classificação final em quatro categorias (muito ativo, ativo, insuficientemente ativo, sedentário). Para realizar essa classificação somam-se a frequência e a duração dos diferentes tipos de atividade (caminhada + atividade moderada + atividade vigorosa). Segundo a classificação do nível de atividade física IPAQ as atividades físicas moderadas são as que precisam de algum esforço físico e que fazem respirar um pouco mais forte que o normal. As atividades físicas vigorosas são entendidas como aquelas que precisam de um grande esforço físico e que fazem respirar muito mais forte que o normal.

As categorias do IPAQ (IPAQ, 2010) são as seguintes:

Sedentário: Não realiza nenhuma atividade física por pelo menos 10 minutos contínuos durante a semana.

Insuficientemente ativo: Realiza atividade física por pelo menos 10 minutos por semana, porém insuficiente para ser classificado como ativo. Pode ser dividido em dois grupos:

A) Atinge pelo menos um dos critérios da recomendação

a) Freqüência: 5dias/semana OU

b) Duração: $150 \mathrm{~min} / \mathrm{semana}$

B) Não atingiu nenhum dos critérios da recomendação 
Neste estudo não foi aplicada a subdivisão da categoria Insuficientemente Ativo.

Ativo: Cumpriu as recomendações

a) Vigorosa: $\geq 3$ dias/sem e $\geq 20$ minutos por sessão.

b) Moderada ou caminhada: $\geq 5$ dias/sem e $\geq 30$ minutos por sessão.

c) Qualquer atividade somada: $\geq 5$ dias/sem e $\geq 150$ minutos/sem (caminhada+moderada+vigorosa)

Muito ativo: Cumpriu as recomendações

a) Vigorosa: $\geq 5$ dias/sem e $\geq 30$ minutos por sessão OU

b) Vigorosa: $\geq 3$ dias/sem e $\geq 20$ minutos por sessão + moderada e/ou caminhada: $\geq 5$ dias/sem e $\geq 30$ minutos por sessão.

Neste estudo as categorias ativo e muito ativo foram agrupadas numa só, devido à baixa freqüência na categoria muito ativo. Essa variável foi tratada como qualitativa ordinal.

\subsubsection{Classe Funcional}

A classe funcional é uma categorização dos diferentes estágios da IC relacionada à limitação para o esforço. Essa classificação possui 4 categorias que refletem a gravidade da doença. A classe funcional foi determinada pela pesquisadora e pela coletadora devidamente treinada, seguindo a diretriz estabelecida pela New York Heart Association - NYHA (Sociedade Brasileira de Cardiologia, 2009).

Classe funcional I - Assintomático nas atividades usuais.

Classe funcional II - Sintomas desencadeados por esforços habituais. 
Classe funcional III - Sintomas presentes aos mínimos esforços.

Classe funcional IV - Sintomas em repouso.

As categorias das classes funcionais III e IV foram agrupadas numa só categoria devido ao pequeno número de pacientes que pertenciam à classe funcional IV. Essa variável foi tratada como qualitativa ordinal.

\subsubsection{Terapia medicamentosa}

A terapia medicamentosa refere-se às drogas instituídas para atender uma condição clínica específica com diferentes combinações e dosagens. A individualização do tratamento na IC se deve, principalmente, ao estágio da doença (classe funcional), tolerância às medicações e resposta terapêutica. Neste estudo, essa variável se restringiu ao uso de: beta-bloqueadores, inibidores da enzima conversora da angiotensina (ECA) e digitálicos que o paciente informou fazer uso no dia da entrevista, dado que foi confirmado pela prescrição em receituário médico que o paciente portava. Essa variável foi operacionalizada como qualitativa nominal.

\subsubsection{Dispnéia}

Dispnéia é um termo utilizado para caracterizar uma experiência subjetiva de desconforto para respirar que varia de intensidade. Para avaliar a dispnéia foi perguntado ao paciente se sentia falta de ar. Nos casos de resposta positiva, solicitou-se informar se a falta de ar estava presente aos pequenos, médios, grandes ou intensos esforços, considerando o desempenho das atividades habituais, que são aquelas realizadas no cotidiano, como cuidados com a casa, compras, etc.

Para categorização do grau de dispnéia em relação às atividades diárias, ou seja, os esforços executados nas ações usuais, foi utilizada a 
classificação contida no Índice de Dispnéia Basal de Mahler (Mahler et al., 1984):

Pequeno - Fica dispnéico com atividades físicas leves tais como caminhar no plano, tomar banho ou ficar de pé.

Moderado (médios) - Fica dispnéico com atividades físicas moderadas, como subir pequenos aclives, subir menos que 3 lances de escada ou carregando volumes leves no plano.

Grande - Fica dispnéico apenas com grandes atividades físicas como subir grandes aclives, subir mais que 3 lances de escada.

Intenso - Fica dispnéico apenas com atividade física intensa, como carregar volumes muito pesados no plano, pesos leves em aclives ou correndo. Sem falta de ar para realização das tarefas habituais.

A variável dispnéia foi tratada como qualitativa nominal (presente/ausente). A variável intensidade do esforço para dispnéia foi tratada como qualitativa ordinal (pequeno, moderado, grande, intenso).

\subsubsection{Tabagismo}

O hábito de fumar foi avaliado por meio da resposta do paciente quanto a ser fumante de cigarros, atual ou pregresso, número de cigarros por dia e tempo de manutenção do hábito (atual ou pregresso). A variável foi tratada como qualitativa. Foram classificados como fumantes os que responderam fumar à época da avaliação e os que informaram ter parado de fumar nos 12 meses anteriores a avaliação. A variável foi tratada como qualitativa nominal. 


\subsubsection{0 Índice de massa Corporal}

O Índice de massa Corporal (IMC) é reconhecido como padrão internacional para avaliar o grau de obesidade (Associação Brasileira para o Estudo da Obesidade e da Síndrome Metabólica, 2009). O IMC é calculado dividindo o peso (em $\mathrm{Kg}$ ) pela altura ao quadrado (em metros). Esta variável foi dicotomizada em $\geq 25,0$ e $<25,0$. Valores acima ou iguais a 25 indicam sobrepeso ou obesidade graus I, II ou III (Associação Brasileira para o Estudo da Obesidade e da Síndrome Metabólica, 2009). A variável foi tratada como qualitativa nominal.

\subsection{INSTRUMENTO}

Foi utilizado um instrumento estruturado (APÊNDICE I) contendo três partes. A primeira parte serviu para o registro dos dados de caracterização pessoal e clínica do paciente. A segunda parte reuniu os formulários padronizados para avaliação de padrão de sono e fadiga; e a terceira parte foi composta pelo IPAQ na versão curta e campos para avaliação e registro dos dados sobre terapia medicamentosa, dispnéia e tabagismo.

\subsection{PROCEDIMENTO DE COLETA DE DADOS}

A coleta de dados foi realizada pela pesquisadora e por uma coletadora enfermeira que estudou o projeto de pesquisa e foi treinada pela pesquisadora para a coleta de dados. No treinamento, a coletadora observou a pesquisadora aplicando o instrumento em 10 pacientes e, logo após, a pesquisadora observou a coletadora fazendo a aplicação. Os equívocos e dúvidas eram então discutidos a fim de calibrar a execução do procedimento e tornar a coleta homogênea. 
O projeto de pesquisa foi submetido ao Comitê de Ética em Pesquisa (CEP) do Instituto Dante Pazzanese de Cardiologia. Cópia do documento da aprovação do CEP consta em anexo (ANEXO I).

O ambulatório funciona todos os dias, exceto aos sábados, domingos e feriados. O fluxo de pacientes e acompanhantes inicia por volta das 7:30 horas e se mantém intenso até as 11:30 da manhã, quando terminam os atendimentos aos pacientes agendados. Para direcionar a coleta de dados, era feito previamente, diariamente e de forma sistemática, uma consulta aos prontuários dos pacientes que seriam atendidos naquele dia. Essa consulta era feita antes dos atendimentos começarem, a fim de detectar os pacientes que seriam incluídos no estudo, de acordo com os critérios já estabelecidos, de conhecer o diagnóstico principal e também as doenças associadas.

Após determinar quais pacientes atendiam aos critérios para fazer parte da pesquisa, antes da consulta médica eles eram convidados a participar do estudo. Esclarecidos da finalidade do estudo e dos seus direitos como participantes, os que aceitaram participar assinaram o Termo de Consentimento Livre e Esclarecido (ANEXO II), atendendo a resolução 196/96 da Comissão Nacional de Ética em Pesquisa (CONEP), após o que foi realizada a coleta de dados por meio de entrevista.

A classe funcional da insuficiência cardíaca de cada paciente era avaliada pela pesquisadora e pela coletadora. Quando havia incerteza ou dúvida, a classe funcional definida era confirmada com os médicos que haviam atendido o paciente.

Antes do início da entrevista, foram verificadas as medidas antropométricas do paciente, a fim de estabelecer o IMC. 


\subsection{ANÁLISE ESTATÍSTICA DOS DADOS}

As respostas dos participantes foram lançadas em um banco de dados eletrônico (SPSS ${ }^{\circledR}$ Version 18) e submetidas a análises estatísticas descritivas e inferenciais.

\subsubsection{Análise univariada}

As diferenças entre os escores totais do PSQI foram analisadas por testes não paramétricos, que compara os postos entre dois ou mais grupos. Os testes não paramétricos foram escolhidos porque os escores do PSQI não apresentaram distribuição normal, conforme avaliado pelo teste de Kolmogorov-Smirnov (Siegel, Castellan, 2006).

A associação entre a categoria de dormidor e as variáveis selecionadas foi analisada pelo teste de Qui-Quadrado, com correção de continuidade de Yates. O teste de Qui-Quadrado aplica-se a variáveis qualitativas nominais e baseia-se nas diferenças entre valores observados e esperados, avaliando se as proporções em cada grupo podem ser consideradas semelhantes ou não (Vieira, 2003). A aproximação pela distribuição Qui-Quadrado da distribuição amostral torna-se mais precisa se uma correção para continuidade for feita. A correção é necessária porque uma distribuição contínua (Qui-Quadrado) é usada para aproximar uma distribuição discreta. Quando todas as freqüências esperadas são pequenas, a aproximação pode ser pobre. O objetivo da correção para continuidade de Yates é remover esta fonte de imprecisão (Siegel, Castellan, 2006).

Nos casos em que uma das variáveis envolveu três categorias ou mais (classe funcional, situação de trabalho) e em que os testes QuiQuadrado geraram valores de $p$ ( $p$-valor) menores do que 0,05, foi aplicada a análise de resíduos para interpretar a contribuição de cada categoria da variável (Pereira, 1999). O resíduo padronizado, que é a diferença entre o valor observado e esperado expresso em unidades de desvio padrão é 
usado para verificar quais categorias estão contribuindo para a associação afirmada pelo Qui-Quadrado. Os resíduos padronizados representam valores de relação biunívoca com probabilidades de ocorrência e, nos casos em que o nível de significância é 0,05 , o resíduo deve ser superior a 1,96 (excesso de ocorrências) ou inferior a - 1,96 (falta de ocorrências) (Pereira, 1999). A análise de resíduos é complementar ao teste em que o QuiQuadrado detecta diferença para auxiliar o pesquisador na interpretação dos resultados.

O teste de Mann-Whitney (Siegel, Castellan, 2006) foi usado para comparar dois grupos independentes, pois não se pôde garantir o pressuposto de distribuição normal dos dados. O teste de Kruskal-Wallis (Siegel, Castellan, 2006) foi aplicado nas situações em que a variável era qualitativa ordinal e o número de grupos era maior que dois.

Em todas as análises o valor de a assumido foi 0,05 .

\subsubsection{Análise múltipla}

Foi realizado um modelo de regressão logística binária. A regressão logística binária é uma técnica estatística que tem como objetivo produzir um modelo que permita descrever o comportamento entre uma variável dependente binária (do tipo sim/não) e variáveis independentes quantitativas e qualitativas (Fávero et al., 2009). Esse modelo foi aplicado para verificar a contribuição das variáveis demográficas e clínicas para a variável dependente 'maus dormidores'. O modelo construído neste trabalho utilizou como variáveis independentes as que apresentaram nos testes univariados valor de $p<0,20$ (valor arbitrado na tentativa de combinar variáveis que poderiam ser significantes no modelo). O teste Omnibus foi realizado para verificar se o modelo ajustado era melhor que o modelo só com a constante. O teste Omnibus é uma medida absoluta de validade do modelo (Meyers et al., 2006). 
Resultados 


\section{RESULTADOS}

Inicialmente serão apresentadas as características demográficas e clínicas da amostra dos pacientes com IC. Depois serão apresentados os resultados sobre sono (escore global e categoria de dormidor) e, a seguir, os resultados das análises das associações entre sono e sexo, idade, escolaridade, convivência marital, situação de trabalho, fadiga, fadiga ao esforço, atividade física, classe funcional terapia medicamentosa, dispnéia, IMC e tabagismo.

\subsection{CARACTERIZAÇÃO DOS PARTICIPANTES}

As características demográficas e clínicas da amostra estão apresentadas na Tabela 1. 
Tabela 1 - Características da amostra (N=400). São Paulo - 2009

\begin{tabular}{|c|c|c|}
\hline Características & $\mathbf{n}$ & $\%$ \\
\hline \multicolumn{3}{|l|}{ Sexo } \\
\hline Masculino & 259 & 64,8 \\
\hline Feminino & 141 & 35,2 \\
\hline \multicolumn{3}{|l|}{ Idade (anos) } \\
\hline Mediana & \multicolumn{2}{|c|}{59} \\
\hline Média (DP) & \multicolumn{2}{|c|}{$57,8(11,6)$} \\
\hline Variação & \multicolumn{2}{|c|}{$21-89$} \\
\hline \multicolumn{3}{|l|}{ Escolaridade (anos) } \\
\hline Mediana & \multicolumn{2}{|c|}{5,0} \\
\hline Média (DP) & \multicolumn{2}{|c|}{$6,1(3,9)$} \\
\hline Variação & \multicolumn{2}{|c|}{$0-18$} \\
\hline \multicolumn{3}{|l|}{ Convivência Marital } \\
\hline Sim & 279 & 69,8 \\
\hline Não & 121 & 30,2 \\
\hline \multicolumn{3}{|l|}{ Situação de Trabalho } \\
\hline Aposentado & 203 & 50,8 \\
\hline Desempregado, Estudante, Do lar & 80 & 20,0 \\
\hline Empregado (ativo) & 78 & 19,5 \\
\hline Afastado/Auxílio doença & 39 & 9,8 \\
\hline \multicolumn{3}{|l|}{ Classe Funcional } \\
\hline I & 59 & 14,8 \\
\hline II & 202 & 50,5 \\
\hline III & 128 & 32,0 \\
\hline IV & 11 & 2,8 \\
\hline \multicolumn{3}{|l|}{ Diagnóstico Médico Principal } \\
\hline Miocardiopatias ${ }^{*}$ & 391 & 97,8 \\
\hline $\mathrm{ICO}$ & 1 & 0,2 \\
\hline Valvopatias & 8 & 2,0 \\
\hline
\end{tabular}

Múltiplas etiologias associadas ou não

Os dados da Tabela 1 mostram que houve predominância do sexo masculino $(64,8 \%)$, que a idade média foi de 57,8 (DP=11,6) anos, e a escolaridade média de 6,1 (DP=3,9) anos de estudo. A maioria dos pacientes é aposentada $(50,8 \%)$ e convive maritalmente $(69,8 \%)$. Quanto à 
classe funcional, houve predomínio da classe funcional II $(50,5 \%)$, seguida da classe funcional III $(32,0 \%)$, classe funcional I $(14,8 \%)$ e finalmente classe funcional IV (2,8\%). As miocardiopatias de diversas etiologias (valvar, chagásicas, coronariana, entre outras) representaram os diagnósticos médicos mais freqüentes $(97,8 \%)$.

\subsection{SONO}

O sono foi avaliado por meio das respostas ao PSQI. As 19 questões do PSQI são agrupadas em 7 componentes com pontuações distribuídas numa escala de 0 a 3 . Os componentes são: qualidade subjetiva do sono, latência do sono, duração do sono, eficiência habitual do sono, transtornos do sono, uso de medicamentos para dormir e disfunção diurna. As pontuações desses componentes são então somadas para produzir um escore global, que varia de 0 a 21, e quanto maior a pontuação, pior a qualidade do sono.

A Tabela 2 mostra os resultados da estatística descritiva dos escores totais e nos componentes do PSQI.

Tabela 2 - Estatística descritiva dos escores nos componentes do PSQI ( $N=400)$. São Paulo - 2009

\begin{tabular}{lccc}
\hline Componentes do PSQI & Média (DP) & IC95\% & Mediana \\
\hline 1. Qualidade subjetiva do sono & $1,53(0,68)$ & {$[1,45 ; 1,60]$} & 1,0 \\
2. Latência do sono & $1,68(1,26)$ & {$[1,56 ; 1,81]$} & 2,0 \\
3. Duração do sono & $1,33(1,08)$ & {$[1,22 ; 1,43]$} & 1,0 \\
4. Eficiência habitual do sono & $1,51(1,32)$ & {$[1,38 ; 1,64]$} & 1,0 \\
5. Transtornos do sono & $1,33(0,60)$ & {$[1,27 ; 1,39]$} & 1,0 \\
6. Uso de medicamentos para dormir & $0,28(0,83)$ & {$[0,19 ; 0,36]$} & 0 \\
7. Disfunção diurna & $1,05(1,13)$ & {$[0,94 ; 1,16]$} & 1,0 \\
\hline Escore global PSQI & $8,70(4,39)$ & {$[8,27 ; 9,14]$} & 9,0 \\
\hline
\end{tabular}


O ponto de corte do PSQI define bons e maus dormidores. Escores no PSQI $\leq 5$ categorizam bons dormidores e escores $>5$ maus dormidores. Dos 400 pacientes estudados, 274 (68,50\% / IC95\% 0,64/0,73) foram categorizados como maus dormidores e 126 (31,50\%) como bons dormidores. Do total da amostra, $53,5 \%$ classificou o sono como bom ou muito bom, e 46,5\% como ruim ou muito ruim. A média de duração diária do sono foi 6 horas (DP $01 \mathrm{~h} 53 \mathrm{~m}$ ). Período de sono noturno menor que 5 horas foi relatado por $21 \%$ dos participantes. O tempo médio de latência do sono foi 42 minutos ( $D P=36$ minutos). Do total de participantes, 37,2\% relataram demorar até 15 minutos para pegar no sono, enquanto que $22,8 \%$ demoravam mais que uma hora. A média habitual da eficiência do sono foi de $72 \%(D P=21,3 \%)$. Cento e quarenta e três pacientes $(35,8 \%)$ tinham eficiência habitual maior ou igual a $85 \%$, e 38,2\% tinham eficiência menor que 65\%. Quanto ao uso de medicamentos para dormir, 89,5\% dos pacientes relataram não usar qualquer medicamento para dormir e 7\% relataram usar medicamento para dormir em pelo menos 3 dias por semana. Grande parte dos pacientes $(47,0 \%)$ relatou não ter qualquer dificuldade para manter-se acordado durante o dia, enquanto $14,5 \%$ tinham grandes dificuldades.

A causa mais freqüente de distúrbios do sono relatados pelos pacientes foi nictúria $(72,2 \%)$, seguida por desconforto respiratório $(40,5 \%)$, dor $(15,0 \%)$ e sonho ruim $(13,5 \%)$.

\subsection{ASSOCIAÇÃO ENTRE SONO E VARIÁVEIS SELECIONADAS}

Nesta seção estão apresentados os resultados das análises das associações entre sono e sexo, idade, escolaridade, convivência marital, situação de trabalho, fadiga e fadiga ao esforço, atividade física, classe funcional da IC, terapia medicamentosa, dispnéia, IMC e tabagismo. 
Os escores do sono foram avaliados de duas formas: escores totais no PSQI e categorias de dormidores (bons e maus dormidores). As associações entre os escores totais no PSQI e variáveis selecionadas foram analisadas por testes não paramétricos, que compara os postos entre dois ou mais grupos, razão pela qual se apresentam os quartis dos escores totais nas escalas (Tabelas 3 e 4 ).

Tabela 3 - Estatística descritiva e p-valor dos testes de associação entre escores totais no PSQI e variáveis sociodemográficas em pacientes com IC $(\mathrm{N}=400)$. São Paulo, 2009

\begin{tabular}{|c|c|c|c|c|c|}
\hline Variáveis & $\begin{array}{c}1^{\circ} \\
\text { Quartil }\end{array}$ & Mediana & $\begin{array}{c}3^{\circ} \\
\text { Quartil }\end{array}$ & Média (DP) & Valor de $p$ \\
\hline \multicolumn{6}{|l|}{ Sexo } \\
\hline Masculino & 5 & 8 & 12 & $8,28(4,31)$ & \multirow{2}{*}{$0,009+$} \\
\hline Feminino & 5 & 10 & 13 & $9,48(4,44)$ & \\
\hline \multicolumn{6}{|l|}{ Idade } \\
\hline$\leq 60$ anos & 5 & 9 & 12 & $8,89(4,44)$ & \multirow{2}{*}{$0,337 \dagger$} \\
\hline$>60$ anos & 5 & 8 & 12 & $8,46(4,31)$ & \\
\hline \multicolumn{6}{|l|}{ Escolaridade } \\
\hline$<$ 8anos & 5 & 9 & 13 & $9,00(4,41)$ & \multirow{2}{*}{$0,096 \dagger$} \\
\hline$\geq 8$ anos & 4 & 8 & 12 & $8,27(4,32)$ & \\
\hline \multicolumn{6}{|l|}{ Convivência Marital } \\
\hline Sim & 5 & 8 & 12 & $8,44(4,35)$ & \multirow{2}{*}{$0,075 \dagger$} \\
\hline Não & 5 & 10 & 13 & $9,31(4,43)$ & \\
\hline \multicolumn{6}{|l|}{ Situação de trabalho } \\
\hline Aposentado & 5 & 9 & 13 & $8,79(4,40)$ & \multirow{4}{*}{$0,013 \ddagger$} \\
\hline Desempregado, Estudante, do Lar & 5,5 & 10 & 13 & $9,46(4,35)$ & \\
\hline Empregado (ativo) & 4 & 7 & 11 & $7,35(4,20)$ & \\
\hline Afastado/Auxílo Doença & 6 & 9 & 13 & $9,41(4,32)$ & \\
\hline
\end{tabular}

† Mann-Whitney

$\ddagger$ Kruskal-Wallis

Das cinco variáveis sociodemográficas estudadas, houve diferença estatisticamente significativa para o sexo $(p=0,009)$, sendo que os escores entre as mulheres $(9,48$; $D P=4,44)$ foram maiores que entre os homens $(8,28 ; \mathrm{DP}=4,31)$ e para a situação de trabalho. Os escores mais baixos 
foram os dos pacientes que estavam empregados e ativos no emprego $(7,35 ; \mathrm{DP}=4,20)$.

Tabela 4 - Estatística descritiva e p-valor dos testes de associação entre escores totais no PSQI e variáveis clínicas em pacientes com IC ( $N=400)$. São Paulo, 2009

\begin{tabular}{|c|c|c|c|c|c|}
\hline Variáveis & $1^{\circ}$ Quartil & Mediana & $3^{\circ}$ Quartil & Média (DP) & Valor de $p$ \\
\hline \multicolumn{6}{|l|}{ Fadiga } \\
\hline $\operatorname{Sim}(D U F S \geq 14.5)$ & 6 & 10 & 13 & $9,45(4,24)$ & \multirow{2}{*}{$0,000 \dagger$} \\
\hline Não (DUFS < 14,5) & 3 & 4 & 7,5 & $5,53(3,50)$ & \\
\hline \multicolumn{6}{|l|}{ Fadiga ao esforço } \\
\hline $\operatorname{Sim}(D E F S \geq 12,5)$ & 5 & 9 & 13 & $9,00(4,38)$ & \multirow{2}{*}{$0,000 \dagger$} \\
\hline Não $(D E F S<12,5)$ & 3 & 5 & 9 & $6,03(3,35)$ & \\
\hline \multicolumn{6}{|l|}{ Atividade Física } \\
\hline Sedentário & 5 & 9 & 13 & $8,89(4,47)$ & \multirow{3}{*}{$0,552 \ddagger$} \\
\hline Insuficientemente Ativo & 5 & 8 & 12 & $8,38(4,31)$ & \\
\hline Ativo & 5 & 8 & 12 & $8,39(4,11)$ & \\
\hline \multicolumn{6}{|l|}{ Classe Funcional } \\
\hline 1 & 4 & 5 & 17 & $7,10(4,09)$ & \multirow{3}{*}{$0,000 \ddagger$} \\
\hline II & 4 & 9 & 12 & $8,42(4,39)$ & \\
\hline III ou IV & 6 & 10 & 14 & $9,80(4,25)$ & \\
\hline \multicolumn{6}{|l|}{ Betabloqueador } \\
\hline Sim & 5 & 9 & 12 & $8,75(4,40)$ & \multirow{2}{*}{$0,518 \dagger$} \\
\hline Não & 4 & 7 & 12 & $8,23(4,22)$ & \\
\hline \multicolumn{6}{|l|}{ Inibidor de ECA } \\
\hline Sim & 5 & 9 & 12 & $8,75(4,39)$ & \multirow{2}{*}{$0,304 \dagger$} \\
\hline Não & 5 & 6 & 10 & $7,56(4,18)$ & \\
\hline \multicolumn{6}{|l|}{ Digital } \\
\hline Sim & 6 & 9 & 12 & $9,30(4,28)$ & \multirow{2}{*}{$0,107 \dagger$} \\
\hline Não & 5 & 8 & 12 & $8,49(4,41)$ & \\
\hline \multicolumn{6}{|l|}{ Dispnéia } \\
\hline Sim & 6 & 10 & 13 & $9,48(4,27)$ & \multirow{2}{*}{$0,000 \dagger$} \\
\hline Não & 3 & 5 & 9 & $6,01(3,67)$ & \\
\hline \multicolumn{6}{|c|}{ Índice de Massa Corporal } \\
\hline$<25$ & 5 & 9 & 13 & $8,77(4,43)$ & \multirow{2}{*}{$0,526 \dagger$} \\
\hline$\geq 25$ & 4 & 9 & 12 & $8,51(4,53)$ & \\
\hline \multicolumn{6}{|l|}{ Tabagismo } \\
\hline Sim & 4 & 8 & 11 & $7,83(4,12)$ & \multirow{2}{*}{$0,254 \dagger$} \\
\hline Não & 5 & 9 & 13 & $8,77(4,40)$ & \\
\hline
\end{tabular}

† Mann-Whitney $\ddagger$ Kruskal-Wallis 
A Tabela 4 mostra as associações entre os escores totais no PSQI e variáveis clínicas, que evidenciou que os escores no PSQI são significativamente maiores entre os pacientes com fadiga $(p=0,000)$, fadiga ao esforço $(p=0,000)$, dispnéia $(p=0,000)$ e em classes funcionais mais elevadas $(p=0,000)$. Para identificar onde estavam as diferenças entre as classes funcionais, foram realizadas as comparações múltiplas para o teste de Kruskal-Wallis (Siegel, Castellan, 2006), que mostrou haver diferença entre as classes II e III/IV e entre I e III/IV. Não houve associação entre escores no PSQI e atividade física, terapia medicamentosa, IMC e tabagismo.

Conforme descrito no método a variável sono também foi analisada em categorias de dormidor segundo ponto de corte no PSQI ( $\leq 5$ bom dormidor / >5 mau dormidor). As Tabelas 5 e 6 mostram os resultados dos testes de associação entre as categorias de dormidor e as variáveis selecionadas. 
Tabela 5 - Estatística descritiva e p-valor dos testes de associação entre categorias de dormidores e variáveis sociodemográficas de pacientes com IC $(\mathrm{N}=400)$. São Paulo, 2009

\begin{tabular}{|c|c|c|c|c|c|c|}
\hline \multirow{2}{*}{ Variáveis } & \multicolumn{2}{|c|}{ Bons Dormidores } & \multicolumn{2}{|c|}{ Maus dormidores } & \multirow{2}{*}{ Total } & \multirow{2}{*}{$\begin{array}{c}\text { Valor de } \\
\mathbf{p}\end{array}$} \\
\hline & $\mathrm{n}$ & $\%$ & $\mathbf{N}$ & $\%$ & & \\
\hline \multicolumn{7}{|l|}{ Sexo } \\
\hline Masculino & 89 & 34,36 & 170 & 65,64 & 259 & \multirow{2}{*}{$0,119 \dagger$} \\
\hline Feminino & 37 & 26,24 & 104 & 73,76 & 141 & \\
\hline \multicolumn{7}{|l|}{ Idade } \\
\hline$\leq 60$ anos & 68 & 29,69 & 161 & 70,31 & 229 & \multirow{2}{*}{ 0,429† } \\
\hline$>60$ anos & 58 & 33,92 & 113 & 66,08 & 171 & \\
\hline \multicolumn{7}{|l|}{ Escolaridade } \\
\hline$<$ 8anos & 75 & 31,78 & 161 & 68,22 & 236 & \multirow{2}{*}{$0,972 \dagger$} \\
\hline$\geq 8$ anos & 51 & 31,10 & 113 & 68,90 & 164 & \\
\hline \multicolumn{7}{|l|}{ Convivência Marital } \\
\hline Sim & 90 & 32,26 & 189 & 67,74 & 279 & \multirow{2}{*}{$0,705 \dagger$} \\
\hline Não & 36 & 29,75 & 85 & 70,25 & 121 & \\
\hline \multicolumn{7}{|l|}{ Situação de trabalho } \\
\hline Aposentado & 62 & 30,54 & 141 & 69,46 & 203 & \multirow{4}{*}{$0,009 \dagger$} \\
\hline Desempregado, Estudante, do Lar & 20 & 25,00 & 60 & 75,00 & 80 & \\
\hline Empregado (ativo) & 36 & 46,15 & 42 & 53,85 & 78 & \\
\hline Afastado/Auxílo Doença & 8 & 20,51 & 31 & 79,49 & 39 & \\
\hline
\end{tabular}

† Qui-quadrado

As proporções entre bons e maus dormidores nas variáveis sociodemográficas foram semelhantes, com exceção da situação de trabalho em que os empregados tiveram maior proporção de bons dormidores que nas outras categorias $(p=0,009)$. Pela análise do resíduo padronizado (Pereira, 1999) detectou-se que o excesso de bons dormidores entre os empregados teve maior responsabilidade pelo resultado do teste de Quiquadrado na variável situação de trabalho. 
Tabela 6 - Estatística descritiva e p-valor dos testes de associação entre categorias de dormidores e variáveis clínicas de pacientes com IC $(N=400)$. São Paulo, 2009

\begin{tabular}{|c|c|c|c|c|c|c|}
\hline \multirow{2}{*}{ Variáveis } & \multicolumn{2}{|c|}{ Bons Dormidores } & \multicolumn{2}{|c|}{ Maus dormidores } & \multirow{2}{*}{ Total } & \multirow{2}{*}{ Valor de $p$} \\
\hline & $\mathbf{n}$ & $\%$ & $\mathbf{n}$ & $\%$ & & \\
\hline \multicolumn{7}{|l|}{ Fadiga } \\
\hline $\operatorname{Sim}(D U F S \geq 14.5)$ & 77 & 23,77 & 247 & 76,23 & 324 & \multirow{2}{*}{$0,000 \dagger$} \\
\hline Não (DUFS < 14,5) & 49 & 64,47 & 27 & 35,53 & 76 & \\
\hline \multicolumn{7}{|l|}{ Fadiga ao esforço } \\
\hline $\operatorname{Sim}(\mathrm{DEFS} \geq 12,5)$ & 91 & 26,92 & 247 & 73,08 & 338 & \multirow{2}{*}{$0,000 \dagger$} \\
\hline Não (DEFS < 12,5) & 35 & 56,45 & 27 & 43,55 & 62 & \\
\hline \multicolumn{7}{|l|}{ Atividade Física } \\
\hline Sedentário & 77 & 30,43 & 176 & 69,57 & 253 & \multirow{3}{*}{$0,806 \dagger$} \\
\hline Insuficientemente Ativo & 36 & 33,96 & 70 & 66,04 & 106 & \\
\hline Ativo & 13 & 31,71 & 28 & 68,29 & 41 & \\
\hline \multicolumn{7}{|l|}{ Classe Funcional } \\
\hline I & 31 & 52,54 & 28 & 47,46 & 59 & \multirow{3}{*}{$0,000 \dagger$} \\
\hline II & 67 & 33,17 & 135 & 66,83 & 202 & \\
\hline III ou IV & 28 & 20,14 & 111 & 79,86 & 139 & \\
\hline \multicolumn{7}{|l|}{ Betabloqueador } \\
\hline Sim & 114 & 30,89 & 255 & 69,11 & 369 & \multirow[t]{2}{*}{$0,485 \dagger$} \\
\hline Não & 12 & 38,71 & 19 & 61,29 & 31 & \\
\hline \multicolumn{7}{|l|}{ Inibidor de ECA } \\
\hline Sim & 119 & 31,07 & 265 & 69,19 & 383 & \multirow{2}{*}{$0,423 \dagger$} \\
\hline Não & 7 & 43,75 & 9 & 56,25 & 16 & \\
\hline \multicolumn{7}{|l|}{ Digital } \\
\hline Sim & 26 & 24,76 & 79 & 75,24 & 105 & \multirow{2}{*}{$0,108 \dagger$} \\
\hline Não & 100 & 33,90 & 195 & 66,10 & 295 & \\
\hline \multicolumn{7}{|l|}{ Dispnéia } \\
\hline Sim & 72 & 23,08 & 240 & 76,92 & 312 & \multirow{2}{*}{$0,000 \dagger$} \\
\hline Não & 54 & 61,36 & 34 & 38,64 & 88 & \\
\hline \multicolumn{7}{|c|}{ Índice de Massa Corporal } \\
\hline$<25$ & 91 & 30,74 & 205 & 69,26 & 296 & \multirow{2}{*}{$0,669+$} \\
\hline$\geq 25$ & 35 & 33,65 & 69 & 66,35 & 104 & \\
\hline \multicolumn{7}{|l|}{ Tabagismo } \\
\hline Sim & 11 & 37,93 & 18 & 62,07 & 29 & \multirow{2}{*}{$0,571 \dagger$} \\
\hline Não & 115 & 31,00 & 256 & 69,00 & 371 & \\
\hline
\end{tabular}

† Qui-quadrado 
A categoria de dormidor foi significativamente associada com algumas das variáveis clínicas. A proporção de maus dormidores foi maior entre os pacientes com fadiga $(p=0,000)$, fadiga ao esforço $(p=0,000)$, dispnéia $(p=0,000)$, e em classes funcionais mais elevadas $(p=0,000)$. A análise do resíduo padronizado mostrou que a diferença está na classe I e na classe III/IV. Na classe I a proporção de maus dormidores é menor do que a de bons dormidores. Na classe III/IV em que a proporção de maus dormidores é maior do que a proporção de bons dormidores.

A tabela 7 sintetiza os principais resultados da análise univariada. 
Mariana Alvina dos Santos

Tabela 7 - Principais resultados dos testes de associação entre as variáveis de sono e outras variáveis selecionadas. São Paulo, 2009.

\begin{tabular}{|c|c|c|}
\hline \multirow{2}{*}{ Variáveis } & \multicolumn{2}{|c|}{ Sono } \\
\hline & PSQI (escore total) & PSQI (maus dormidores) \\
\hline \multirow[t]{2}{*}{ Sexo } & $\mathrm{F}>\mathrm{M}$ & $\mathrm{F}=\mathrm{M}$ \\
\hline & $p=0,009$ & $p=0,119$ \\
\hline \multirow[t]{2}{*}{ Faixa etária } & $\leq 60$ anos $=>60$ anos & $\leq 60$ anos $=\square 60$ anos \\
\hline & $p=0,337$ & $p=0,429$ \\
\hline \multirow[t]{2}{*}{ Escolaridade } & $\square$ 8anos $=\geq 8$ anos & $\square$ 8anos $=\geq 8$ anos \\
\hline & $\mathrm{p}=0,096$ & $\mathrm{p}=0,972$ \\
\hline \multirow[t]{2}{*}{ Convivência marital } & Sim=Não & Sim=Não \\
\hline & $p=0,075$ & $p=0,705$ \\
\hline \multirow[t]{2}{*}{$\begin{array}{l}\text { Situação de trabalho } \\
\text { (empregado e ativo) }\end{array}$} & Empregados $<$ Outras categorias & Empregados $<$ Outras categorias \\
\hline & $p=0,013$ & $p=0,009$ \\
\hline \multirow[t]{2}{*}{ Fadiga } & Sim> Não & Sim> Não \\
\hline & $p=0,000$ & $p=0,000$ \\
\hline \multirow[t]{2}{*}{ Fadiga ao esforço } & Sim> Não & Sim> Não \\
\hline & $p=0,000$ & $p=0,000$ \\
\hline \multirow[t]{2}{*}{ Atividade física } & ins. ativo $=$ ativo $=$ sed & ins. ativo $=$ ativo $=$ sed \\
\hline & $p=0,552$ & $p=0,806$ \\
\hline \multirow[t]{2}{*}{ Classe Funcional } & $\mathrm{CFI}=\mathrm{CFII}<\mathrm{CF} \| \mathrm{II} / \mathrm{IV}$ & $\mathrm{CF}$ I $<$ CFII $<$ CF III/IV \\
\hline & $p=0,000$ & $p=0,000$ \\
\hline \multirow[t]{2}{*}{ Betabloqueador } & Sim=Não & Sim=Não \\
\hline & $p=0,518$ & $p=0,485$ \\
\hline \multirow[t]{2}{*}{ Inibidor de ECA } & Sim= Não & Sim= Não \\
\hline & $p=0,304$ & $p=0,423$ \\
\hline \multirow[t]{2}{*}{ Digital } & Sim= Não & Sim=Não \\
\hline & $p=0,107$ & $p=0,108$ \\
\hline \multirow[t]{2}{*}{ Dispnéia } & Sim> Não & Sim> Não \\
\hline & $p=0,000$ & $p=0,000$ \\
\hline \multirow{3}{*}{$\begin{array}{l}\text { Índice de Massa } \\
\text { Corporal }\end{array}$} & & \\
\hline & Sim=Não & Sim= Não \\
\hline & $p=0,526$ & $p=0,669$ \\
\hline Tabagismo & $\begin{array}{l}\text { Sim= Não } \\
p=0,254\end{array}$ & $\begin{array}{l}\text { Sim= Não } \\
p=0,571\end{array}$ \\
\hline
\end{tabular}




\subsection{ANÁLISE MÚLTIPLA}

Com a finalidade de identificar as variáveis independentemente associadas à categoria de dormidor, as variáveis que apresentaram valores de $p$ menores que 0,20 na análise univariada foram submetidas à regressão logística binária. As variáveis preditoras que entraram no modelo foram: sexo (masculino/feminino), dispnéia (sim/não), fadiga ao esforço (DEFS $<12,5$ ou DEFS $\geq 12,5$ ), fadiga (DUFS $<14,5$ ou DUFS $\geq 14,5$ ), uso de digitálico (sim/não); classe funcional (I, II, e III/IV) e situação de trabalho (empregado/não empregado). $O$ resultado da regressão logística indicou que o modelo ajustado é significativo (Teste Omnibus - $p=0,000$ ). A Tabela 8 apresenta os resultados da regressão logística binária somente para as duas variáveis que apresentaram significância estatística, com o coeficiente $B, a$ estatística de Wald, a significância, a razão de chance (odds ratio - OR) e o Intervalo de Confiança da OR.

Tabela 8 - Resultados da regressão logística para preditores de categoria de mau dormidor no PSQI.

\begin{tabular}{|c|c|c|c|c|c|c|}
\hline \multirow{2}{*}{ Variável } & \multirow{2}{*}{ B } & \multirow{2}{*}{ Wald } & \multirow{2}{*}{ Valor-p } & \multirow{2}{*}{ OR } & \multicolumn{2}{|c|}{ IC 95\% } \\
\hline & & & & & Inferior & Superior \\
\hline Dispnéia & 1,17 & 13,27 & 0,000 & 3,23 & 1,72 & 6,07 \\
\hline $\begin{array}{l}\text { Fadiga } \\
\text { (DUFs } \geq 14,5 \text { ) }\end{array}$ & 1,24 & 14,59 & 0,000 & 3,45 & 1,82 & 6,49 \\
\hline
\end{tabular}

Os resultados da Tabela 8 mostram que a presença de dispnéia aumenta em 3,23 vezes a chance de ser mau dormidor; e a presença de fadiga, em 3,45. 
Discussão 


\section{DISCUSSÃO}

A avaliação de 400 pacientes ambulatoriais com insuficiência cardíaca forneceu dados que permitiram caracterizar o padrão de sono em relação a outras variáveis.

O padrão de sono foi estudado por meio do PSQI que fornece escores totais que permitem categorizar os respondentes em bons ou maus dormidores. Os resultados serão discutidos quanto aos escores totais no PSQI (variável contínua) e segundo as categorias de dormidor (variável categórica).

\subsection{CARACTERIZAÇÃO DOS PARTICIPANTES}

Participaram do estudo 400 pacientes ambulatoriais com IC. Quanto às características dos pacientes houve predominância de classes funcionais I e II que totalizaram $50,5 \%$ da amostra. No entanto, vale destacar o grande número de pacientes em classes funcionais mais elevadas III e IV $(34,8 \%)$, o que não era esperado visto a amostra ser de pacientes ambulatoriais, ou seja, mais estáveis e compensados. Em estudo realizado com 300 pacientes no mesmo local no ano de 2008, houve predominância de classes funcionais I e II, totalizando $83,4 \%$ da amostra (Fini, 2008), ou seja, pacientes menos graves.

\subsection{SONO}

As alterações de sono têm sido descritas como freqüentes e comuns entre os pacientes com IC (Manochia et al., 2001; Brostrom et al., 2001; Redeker, Hilkert, 2005; Phillips, 2005; Riegel, Weaver, 2009), além de ser um dos sintomas de mais incômodo para essa população (Zambroski et al., 
2005). Os resultados deste estudo, em relação ao padrão do sono do paciente com IC, são semelhantes aos de outros estudos em pacientes com IC e com outras doenças crônicas.

A prevalência de "maus dormidores" na amostra deste estudo ( $n=400$ pacientes com IC) foi de $68,5 \%$. Outros estudos com amostras de pacientes com IC mostraram prevalência variando de 37,0\% (Skobel et al., 2005) a 74,4\% (Chen, Clark, 2009). Para comparar os resultados é importante considerar o ponto de corte usado pelos autores para definir os casos de maus dormidores, entre outras características dos estudos. No presente estudo, escores maiores que 5 foram categorizados como maus dormidores, conforme a definição do autor do PSQI (Buysse et al., 1989). Assim, achados similares aos do presente estudo foram encontrados no estudo de Redeker e Stein (2006), com 59 pacientes com IC, em que identificou 67,8\% de maus dormidores; e no de Chen e Clark (2009), com 125 pacientes com IC, em que a proporção de maus dormidores foi $74,4 \%$. Nesses dois estudos o corte utilizado para maus dormidores foi o mesmo que o usado na amostra deste estudo, além do que as amostras também eram de pacientes ambulatoriais com classes funcionais semelhantes às deste estudo. No estudo de Skobel et al. (2005), com amostra de 69 pacientes com IC, a proporção de maus dormidores foi $37,0 \%$. Essa proporção mais baixa que as encontradas nos outros estudos mencionados é provavelmente decorrente do ponto de corte usado (PSQI $\square 10$ ) (Skobel et al., 2005). Não há indicação do motivo pelo qual o autor usou esse ponto de corte.

Em outras doenças crônicas foram encontradas proporções variáveis de maus dormidores (de $30 \%$ a $96 \%$ ), em sua maioria bastante diferentes das encontradas no presente estudo. Sabatini et al. (2005), em estudo com 301 pacientes com doença renal, encontrou 52,5\% de maus dormidores e, Ceolim e Corrêa (2008), em 50 pacientes idosos com vasculopatia periférica, encontrou $70 \%$ de maus dormidores. Eryilmaz et al. (2005), em estudo com 100 pacientes transplantados renais e lliescu et al. (2003), com 89 pacientes em tratamento de hemodiálise encontraram proporções de $30 \%$ e $71 \%$, respectivamente, de maus dormidores. Resultados similares foram 
encontrados entre as amostras de pacientes hipertensos (Alebiosu et al., 2009) e com esclerose múltipla (Merlino et al., 2009) $42,4 \%$ de maus dormidores entre os 80 hipertensos avaliados e $47,5 \%$ entre os 120 pacientes de esclerose múltipla. O estudo realizado por Mahfoud et al. (2009) foi o que apresentou maior proporção de maus dormidores, 96\% entre os sujeitos com história de abuso de substâncias. Vale ressaltar que todos esses autores utilizaram o ponto de corte sugerido pelo autor do instrumento (Buysse et al., 1989). Sayar et al. (2002) que avaliou o sono em 40 pacientes com dor crônica, e Costa et al.(2005) em 100 pacientes com lúpus eritomatoso sistêmico, encontraram, respectivamente uma proporção de $57,5 \%$ e $56 \%$, ambos uitlizando o corte no PSQI maior que 6 . Esses autores não deixam claro o porquê desse corte ter sido usado.

A proporção de maus dormidores na amostra deste estudo é relevante se comparada com outras doenças crônicas. Conhecer a prevalência de maus dormidores ou de distúrbios do sono em população geral é importante para avaliar a magnitude do problema entre os pacientes com doenças crônicas e especialmente entre os pacientes com IC. Embora as estimativas das taxas de distúrbio do sono na população geral variem, dados sugerem que esse é um problema comum, mesmo numa prevalência menor do que em pacientes com IC ( Erickson et al., 2003; Bronstrom et al., 2004). Em uma pesquisa realizada em 2005 por meio de consulta telefônica, pelo "National Sleep In America Poll” com 1506 adultos, 49\% relataram ter uma boa noite de sono habitualmente. Os demais relataram queixas específicas que ocorrem pelo menos em algumas noites da semana, como dificuldade em iniciar o sono (21\%), acordar com freqüência (32\%) e dificuldade em retornar ao sono após despertar (32\%) (National Sleep Foundation, 2005). Em estudo austríaco com amostra de 478 adultos em população geral, o autor evidenciou alterações do sono como, distúrbios e latência prolongada do sono presente em 18\% (Zeitlhofer et al., 2010). Proporções de $26,4 \%$ de maus dormidores entre os homens e $31,1 \%$ entre as mulheres foram observadas em estudo realizado com 1871 adultos selecionados de uma amostra censitária no Japão utilizando o ponto de 
corte original do PSQI (Doi et al., 2001). Redeker e Stein (2006) encontrou $50,8 \%$ de maus dormidores no grupo controle composto por 59 adultos sem doença crônica. Embora esses dados sejam difíceis de comparar com os dados obtidos em pacientes com IC devido aos diferentes métodos de mensuração, eles confirmam que os problemas de sono entre pacientes com IC são muito importantes.

Em síntese, a proporção de maus dormidores entre os pacientes com IC está entre as mais altas identificadas nos estudos com adultos com doenças crônicas e é superior às prevalências encontradas em amostras de população geral.

Quanto ao escores no PSQI, os resultados do estudo de Chen et al. (2009) com 125 pacientes com IC foram, no geral, semelhantes aos do presente estudo. O escore global médio no PSQI neste estudo foi de 8,70 $(\mathrm{DP}=4,39)$ (Tabela 2) e no de Chen foi de 9,06(DP=4,64); períodos de sono noturno menores que cinco horas foram relatados por $21 \%$ dos participantes deste estudo e por $25,6 \%$ no estudo de Chen et al. (2009); demora para pegar no sono superior a uma hora foi relatada por $22,8 \%$ dos pacientes deste estudo, enquanto que no estudo de comparação foi relatado por $19,2 \%$.

Dois resultados discordantes entre os estudos, no que se refere ao padrão do sono, foram quanto ao uso de medicamento para dormir e quanto à disfunção diurna. No estudo de Chen et al. (2009) 14,4\% dos pacientes relataram usar medicamento para dormir pelo menos três vezes por semana, enquanto em nosso estudo foram apenas 7,0\%. Essa diferença entre os dois estudos levantam algumas questões cujas respostas fogem ao objetivo deste trabalho, mas merecem ser consideradas. Pode-se admitir que o padrão de sono entre os pacientes deste estudo e o de Chen et al. (2009) são semelhantes, mas num deles maior parte da amostra usa medicamentos para dormir pelo menos três vezes por semana. Essa diferença poderia ser explicada por pelo menos três razões: 1) o uso de medicamentos tem eficácia questionável para a qualidade do padrão de sono dos pacientes com 
IC, pois mesmo mais medicados os pacientes do estudo de Chen et al. (2009) tiveram escores semelhantes aos deste estudo; 2) a amostra do estudo de Chen et al. (2009) tem problemas de sono mais sérios que o da amostra deste estudo, admitindo-se que só tem escores no PSQI semelhantes porque usa mais medicamentos para dormir; 3) no ambiente em que o estudo de Chen et al. (2009) foi realizado a valorização do sono é maior, levando a maior freqüência de intervenção farmacológica.

Quanto à disfunção diurna, Chen et al. (2009) observou que 9,6\% tinham graves dificuldades para se manter acordados durante o dia, o que foi relatado por $14,5 \%$ dos pacientes deste estudo. Em estudo sobre a sonolência diurna em 4578 adultos, observou-se que o não uso de medicamentos para dormir estava associado com alta freqüência de sonolência diurna (Whitney et al., 1998), o poderia eventualmente explicar as diferenças de sonolência diurna entre os resultados deste estudo e o de Chen et al. (2009).

Considerando-se os escores do PSQI em população geral, em estudo com amostra de 1871 sujeitos Doi et al. (2001) observou escores globais médios do PSQI variando entre 4,00 (DP=2,59) e 6,75 (DP=4,10), sugerindo que as alterações no padrão do sono dos pacientes com IC são relevantes, pois a média do escore global no PSQI foi 8,70 (DP=4,39) (Tabela 2)

\subsection{Associação entre sono e variáveis selecionadas}

Estudos mostram que as complicações do sono são experenciadas de maneira diferente por homens e mulheres (Grandner et al., 2010). Associações entre sono e variáveis selecionadas foram testadas na amostra estudada. Os resultados mostraram que o escore total no PSQI foi mais elevado entre as mulheres ( $p=0,009)$ (Tabela 3 ), mas não houve diferença entre os sexos quanto a categorias de dormidor. Esses resultados contrariam pesquisas realizadas por Sá (2006) e Paulino et al. (2009), que mostraram maior prevalência de alterações do sono em pacientes do sexo masculino. No estudo de Sá (2006), com 13 pacientes com IC, observaramse mais distúrbios respiratórios do sono entre os homens. Também no 
estudo de Paulino et al. (2009) observou-se maior prevalência e intensidade de distúrbios do sono em pacientes do sexo masculino com IC. O mesmo não ocorreu em estudo realizado com amostra de 1871 adultos na população geral, em que a proporção de maus dormidores foi mais elevada entre as mulheres (Doi et al., 2001). Talvez essas diferenças se expliquem pelos diferentes métodos de avaliação do padrão de sono, pois em alguns estudos a avaliação foi feita por meio do PSQI (Doi et al., 2001), e em outros por polissonografia (Sá, 2006; Paulino et al., 2009).

Outra variável sóciodemográfica associada ao sono na amostra deste estudo foi a situação de trabalho. Observou-se que a proporção mais elevada de bons dormidores entre os que estavam empregados, comparados aos que estavam aposentados, desempregados ou afastados do trabalho, foi o que contribuiu para a diferença estatística obtida (Tabela 3). Ao testar a associação entre classe funcional e situação de trabalho (em duas categorias: 1) empregado atualmente ativo e 2) não empregado ou não ativo no trabalho atualmente) verificou-se que os pacientes em classes funcionais mais elevadas estavam entre os não empregados $(p=0,000)$. Ou seja, pior padrão de sono entre os não empregados ou não ativos na época do estudo pode ser decorrente de maior gravidade da IC nesse grupo. Apesar disso, outros estudos sobre sono e situação de trabalho entre os pacientes com IC são necessários, pois Chen et al. (2009) identificou que $6,9 \%$ da variância dos distúrbios de sono foi explicada por limitações na função social, avaliada pelo Health Related Quality of Life. Os participantes que tinham maiores limitações nas diversas atividades sociais, incluindo o trabalho, tinham mais dificuldades no sono (Chen et al., 2009).

$\mathrm{Na}$ amostra deste estudo não houve associação entre o padrão de sono e as variáveis idade, escolaridade e convivência marital (Tabela 3). Esses resultados são controversos. A variável idade foi associada a pior qualidade do sono no estudo realizado por Eryilmaz et al. (2005), em que os maus dormidores eram mais jovens. No que diz respeito à variável escolaridade, os resultados deste estudo são diferentes dos de Chen et al. (2009) e Eryilmaz et al. (2005), nos quais foi evidenciado que maior grau de 
instrução está associado a um sono de melhor qualidade, e também do estudo de Grandner et al. (2010), que encontrou que altos níveis de educação estão associados com menos complicações no sono. Esse resultado é consistente com o estudo Coronary Artery Risk Development in Young Adults, que mostra que maior nível educacional é correlacionado com um sono eficiente (Lauderdale et al., 2006). No presente estudo a escolaridade média da amostra foi de 6,1 (DP=3,9) anos (Tabela 1), destacando-se que $54,2 \%$ tinham no máximo 5 anos de escolaridade. A ausência de associação significante entre escolaridade e padrão de sono nessa amostra pode ser decorrente de baixa variabilidade na escolaridade da amostra.

A associação entre convivência marital e qualidade do sono é controvertida na literatura, mas há evidências de que ela pode influenciar na qualidade do sono (Troxel et al., 2007; Grandner et al., 2010). Estudo qualitativo sugere que problemas de sono em um dos parceiros influenciam negativamente a convivência marital (Rosenblatt, 2006). No estudo de Eryilmaz et al. (2005) com 100 pacientes transplantados renais, assim como no presente estudo, não foi observada associação entre convivência marital e sono. É importante ressaltar que os estudos sobre sono e convivência marital focalizam principalmente os efeitos que os distúrbios podem ter na qualidade dos relacionamentos entre parceiros, mas aceita-se que a convivência marital pode ser um fator de proteção para as queixas de sono (Grandner et al., 2010).

Das 10 variáveis clínicas estudadas, 4 foram associadas significativamente com o padrão do sono (escore total no PSQI e categoria de dormidor): fadiga, fadiga ao esforço, dispnéia e classe funcional da IC.

As variáveis fadiga e fadiga ao esforço mostraram ter associação com o padrão de sono, tanto no que se refere aos escores totais $(p=0,000)$ (Tabela 4), como na categoria de dormidor $(p=0,000)$ (Tabela 6). A fadiga é uma manifestação clínica importante e freqüente na IC. Estudo recente realizado no mesmo local e com população semelhante a deste estudo 
mostrou que o distúrbio do sono foi estatisticamente associado às variáveis de fadiga, e que intensidades de fadiga e de fadiga ao esforço foram mais altas entre os pacientes com distúrbios do sono (Fini, 2008). Em estudo com 138 pacientes com IC, Tiesinga et al. (1998) observaram que a qualidade do sono foi significativamente mais elevada nos pacientes com menor intensidade de fadiga ou de fadiga ao esforço. Estudos com amostra de pacientes com outras doenças crônicas mostram resultados semelhantes (Belza et al., 1993; Crosby 1991; Friedman, H, 1993; Valdini et al., 1987; Van Diest, Apples, 1991)

Assim como a fadiga, a dispnéia é um sintoma comum na IC (Ramasamy et al., 2006). Freqüentemente, os pacientes com IC têm suas funções limitadas pela dispnéia, sintoma de pior evolução com o avançar da doença (Guimarães et al., 1999; Ekman et al., 2005) e sabe-se que distúrbios respiratórios podem interferir no sono ( Phillips, 2005; Chen, Clark, 2007; Hayes et al., 2009; Hagenah, Beil, 2009). Sendo assim, é pertinente verificar se há associação entre dispnéia e padrão de sono nos pacientes com IC. Na amostra deste estudo observou-se associação significante entre a presença de dispnéia e escores mais elevados no PSQI $(p=0,000)$ (Tabela 4), assim como entre dispnéia e categoria de mau dormidor $(p=0,000)$ (Tabela 6). As causas da insônia na IC são atribuídas à dispnéia, ortopnéia, e à dispnéia paroxística noturna por levarem à fragmentação e dificuldade em manter o sono (Chen, Clark, 2007; Hayes et al., 2009; Sassanabe, Shiomi, 2009). E a presença de dispnéia paroxística noturna é considerada um fator de risco para os distúrbios do sono (Príncipe-Rodriguez et al., 2005).

Não foram encontrados estudos de associação entre dispnéia e sono, apenas relatos de ocorrência alta (79,8\%-89\%) de dispnéia entre os pacientes de IC (Martin-Pfitzenmeyer et al., 2009; Ahmed et al., 2004). Porém há freqüentes relatos de distúrbios respiratórios do sono, especialmente entre os pacientes com IC. Estudo realizado por Midgren et al. (2010) com 182 pacientes de IC, evidenciou índice elevado de apnéiahipopnéia em $1 / 3$ deles durante o sono, porém este fato não foi associado a 
pior qualidade de vida ou a sonolência diurna. Redeker et al. (2010), que avaliou 170 pacientes com IC, encontrou 51\% com distúrbios respiratórios durante o sono (avaliados por polissonografia, PSQI e actigrafia). No entanto, não encontrou associação dessa variável com a qualidade do sono por auto-relato. Não é possível comparar resultados de estudos sobre os distúrbios respiratórios do sono com os encontrados neste estudo, pois aqui foi avaliada a dispnéia ao esforço. Sugere-se que outros estudos sobre sono em pacientes com IC considerem a inclusão de variáveis como ortopnéia e dispnéia paroxística noturna.

A classe funcional indica o grau de comprometimento do estado funcional dos pacientes com IC (Miller-Davis et al., 2006) e o grau de agravamento da IC deve ser considerado em estudos do sono, pois se admite que a qualidade do sono seja pior em classes funcionais mais elevadas (Príncipe-Rodriguez et al., 2005). Neste estudo observou-se que os pacientes das classes funcionais mais elevadas têm pior qualidade de sono tanto nos escores totais $(p=0,000)$ (Tabela 4$)$ como na categorização de dormidor $(p=0,000)$ (Tabela 6). Resultados semelhantes foram encontrados por Príncipe-Rodriguez et al. (2005), com 201 pacientes com IC, em que verificou que $53 \%$ das desordens de sono ocorreram em classes funcionais mais elevadas. A mesma relação ocorreu no estudo de Chen et al. (2009) que encontrou mais distúrbios do sono em pacientes em classes funcionais mais elevadas.

As variáveis atividade física, terapia medicamentosa, índice de massa corporal e tabagismo não apresentaram associação com o padrão do sono na amostra deste estudo (Tabela 6).

A associação entre atividade física e sono é pouco explorada nos estudos, porém é de grande importância para propostas de melhora na qualidade de vida das pessoas com alterações do sono. Estudo realizado por Paparrigopoulos et al. (2008), que avaliou a relação entre atividade física (medida pelo IPAQ) e insônia em 1005 participantes com doenças físicas incapacitantes importantes, entre elas a IC, mostrou que a prevalência de 
insônia na amostra total foi de $25,3 \%$ e que, indivíduos que realizavam atividade física moderada-vigorosa eram 56\% menos propensos a ter insônia. Além disso, a análise múltipla revelou interação significativa da atividade física com a presença de IC ou isquemia miocárdica, indicando que indivíduos com atividade física moderada-vigorosa e IC tiveram menor chance de ter insônia se comparados aos indivíduos com problemas cardíacos e baixos níveis da atividade física. Segundo a III Diretriz Brasileira de Insuficiência Cardíaca Crônica (Sociedade Brasileira de Cardiologia, 2009), a realização de atividade física em pacientes de IC, além de ser segura e não aumentar a mortalidade, melhora a qualidade de vida e o desempenho funcional, apesar de poucos estudos mostrarem seus efeitos a longo prazo. Tradicionalmente, a atividade física recomendada como exercício aeróbico é a caminhada, mas recentemente, a atividade física intervalada tem sido demonstrada como método efetivo, seguro e bem tolerado em pacientes com IC (Wisloff et al., 2007). Programas de treinamento físico domiciliar (Niebauer et al., 2005), hidroterapia (Schmid et al., 2007), yoga (Pullen et al., 2008), meditação (Curiati et al., 2005) e tai chi chuan (Yeh et al., 2004) também têm sido propostos alternativamente para pacientes com IC. Esses programas parecem ser seguros e efetivos em diminuir sintomas e melhorar a qualidade de vida de pacientes com IC. Considerando que o sono é componente da qualidade de vida, é razoável admitir-se a possibilidade de a atividade física também influenciar positivamente a qualidade do sono.

A baixa freqüência de pacientes muito ativos pode ter contribuído para a ausência de associação entre atividade física e sono neste estudo.

Quanto à terapia medicamentosa, foram estudados os três grupos de drogas mais freqüentes no tratamento da IC. Não houve associação significativa do sono e a terapia medicamentosa (Tabela 6). O regime terapêutico comumente usado na IC pode contribuir para um sono de má qualidade (Qureshi, Lee-Chiong, 2004). Há suspeita de que o uso de algumas classes de beta-bloqueadores poderiam ter efeitos piores nas características do sono (Yilmaz et al., 2008), possivelmente por provocarem 
diminuição na produção noturna de melatonina (Zisapel, 2007). Porém, estudo realizado por Yumino et al. (2009) com 218 pacientes com IC, mostrou que o uso de betabloqueadores não está associado à prevalência de distúrbios respiratórios do sono nessa população. Estas controvérsias sugerem a necessidade de estudos que esclareçam melhor a interação do padrão do sono e terapia medicamentosa.

O progressivo aumento da prevalência de sobrepeso e obesidade na população contribui para maior prevalência dos distúrbios do sono (Sousa et al., 2008). Mas no presente estudo não houve associação significante entre o sono e IMC acima de 25 (Tabela 6), que indica sobrepeso e obesidade graus I, II ou III (Associação Brasileira para o Estudo de Obesidade e da Síndrome, 2009). Em 203 pacientes com IC foi evidenciado 71\% de apnéia obstrutiva do sono, por meio de polissonografia, e o grupo de pacientes com essa condição tinha IMC mais elevado que o grupo de pacientes com respiração Cheyne-Stokes e que o grupo sem distúrbios respiratórios do sono (Schulz et al., 2007). Estudo realizado por Príncipe-Rodriguez et al. (2005), com 201 pacientes de IC para avaliar os sintomas do sono, mostrou que houve associação entre apnéia obstrutiva do sono e IMC $(p<0,001)$. No entanto, é importante ressaltar que o fato de ter distúrbio respiratório do sono não implica em sua pior qualidade (Midgren et al., 2010; Redeker et al., 2010).

Há indicativos de que o hábito de fumar cigarros interfere negativamente no sono (Sahlin et al., 2009; Jaehne et al., 2009) e na qualidade de vida de pacientes com IC (Conard et al., 2009). No entanto, não foi observada associação entre tabagismo e sono na amostra deste estudo (Tabela 6). É importante observar que neste estudo o hábito de fumar foi categorizado em fumante ou não fumante. A categoria de não fumantes incluiu todos os que referiram nunca ter fumado ou não ter fumado nos últimos doze meses. Qualquer paciente que referisse ter fumado nos últimos doze meses foi considerado fumante. No estudo de Conard et al. (2009) foram usadas três categorias (nunca fumou, ex-fumante, fumou no último mês) e 'fumou no último mês' foi considerado o fumante atual. Portanto, o 
presente estudo ampliou a categoria de fumantes atuais (fumou nos últimos doze meses). Certamente definições mais restritivas quanto ao fumante atual levariam a resultados diferentes.

Os resultados da regressão logística para a categoria de dormidor mostraram que a presença de dispnéia e a fadiga foram preditores significantes de 'maus dormidores' (Tabela 8).

Estudos que incluíram análises múltiplas para investigar variáveis preditivas do sono diferem nas variáveis incluídas. A mesma combinação de variáveis incluídas neste estudo não foi encontrada em qualquer outro o que dificulta a comparação dos resultados. Identificamos dois estudos com objetivo de verificar variáveis preditoras do sono em pacientes com IC. Num deles, realizado com 125 pacientes com IC, cinco preditores (escolaridade, funcionamento social, sintomas físicos, classe funcional e saúde percebida) foram identificados usando o modelo hierárquico de regressão múltipla, explicando $26,9 \%$ da variância nos distúrbios do sono (Chen et al., 2009). No outro, realizado com amostra de 84 pacientes de IC foram testadas variáveis fisiológicas potencialmente preditoras dos distúrbios do sono (Erickson et al., 2003). Os autores observaram que a classe funcional, idade, sexo, etiologia, obesidade, hábito de fumar e uso de betabloqueadores não foram preditores de distúrbios do sono (Erickson et al., 2003). No entanto, é importante observar que, apesar de no resumo os autores referirem ter realizado regressão logística, não se encontra no corpo do texto os resultados que permitam analisar adequadamente o modelo da regressão logística.

Mantida a ressalva ao estudo de Erickson et al., (2003), podemos afirmar que a contribuição da gravidade da IC (CF) tem resultados controversos, pois num dos estudos observou-se que a CF contribuiu em 10\% para explicar a variância nos escores do PSQI (Chen et al., 2009). Por outro lado, parece haver concordância quanto a contribuição dos sintomas físicos para os problemas de sono na IC. Se considerarmos que a fadiga e dispnéia são sintomas físicos frequentes entre os pacientes com IC, 
podemos admitir que os resultados deste estudo são concordantes com os de Chen et al. (2009).

Em estudos com pacientes com outras doenças crônicas encontramse resultados que mostram variáveis como IMC e saúde física (Eryilmaz et al., 2005); sedentarismo (Paparrigopoulos et al., 2008; Costa et al., 2005); depressão ou outras variáveis psicossociais (Costa et al., 2005; Tsai et al., 2009; Sabatini et al., 2005) como preditoras de problemas do sono.

Neste estudo, a presença de fadiga e a de dispnéia aumentaram, de forma independente, a chance de ser mau dormidor. No entanto, outros estudos sobre variáveis preditoras da qualidade do sono em pacientes com IC, incluindo variáveis psicossociais e de sintomas físicos são necessários para melhor compreender a interação e a importância dos fatores correlatos aos problemas do sono nessa população. 


\section{Conclusões}




\section{CONCLUSÕES}

A avaliação da amostra dos 400 pacientes com insuficiência cardíaca permitiu concluir que:

1. A qualidade do padrão do sono é pior quando comparada a amostras de população geral;

2. A proporção de maus dormidores é maior quando comparada a amostras de população geral;

3. Altos escores no PSQI e ser mau dormidor foram associados a: situação de não estar trabalhando, classes funcionais mais elevadas, presença de fadiga, de fadiga ao esforço e de dispnéia. Ser do sexo feminino foi associado a escores mais elevados no PSQI;

4. A presença de fadiga e a de dispnéia aumentaram, de forma independente, a chance de ser mau dormidor.

O padrão do sono é, portanto, uma variável complexa, que pode ter impacto importante em várias esferas da vida dos pacientes. 


\section{Implicações e limitações do estudo}




\section{IMPLICAÇÕES E LIMITAÇÕES DO ESTUDO}

Das possíveis implicações dos resultados deste estudo, pode-se afirmar que avaliação do padrão de sono dos pacientes com IC precisa ser cuidadosa e realizada desde o início do tratamento. A detecção precoce dos problemas de sono nos pacientes de IC e a adoção de medidas para controlá-los podem trazer benefícios para os pacientes.

Poucos estudos sobre a perspectiva do paciente com IC sobre os distúrbios do sono têm sido realizados. Mas, é importante ressaltar a necessidade de os pacientes estarem aptos a avaliar a qualidade do próprio sono e os efeitos negativos de um padrão de sono insatisfatório, para que possam ser impulsionados a verbalizar esse problema aos profissionais de saúde. Compreender a inter-relação dos diferentes sintomas ou manifestações da doença ajudará o paciente a fazer avaliações contextualizadas da sua própria evolução. Por outro lado, os profissionais de saúde precisam mostrar atitudes positivas em relação a avaliação do sono como elemento importante da saúde, desenvolvendo habilidades para sua avaliação e diagnóstico dos problemas de sono, também de forma contextualizada. Isto é, considerando a multidimensionalidade e interação dos diversos sintomas e manifestações da IC.

Pode-se afirmar que estudos sobre o sono em pacientes com IC não são escassos, mas resultados inconsistentes, amostras pequenas e medidas diversificadas das variáveis mostram a necessidade de prosseguir a investigação para explorar a natureza do sono e seus efeitos sobre a saúde de pessoas vivendo com IC. São especialmente importantes os estudos de intervenções, para melhorar a qualidade do padrão de sono dos pacientes com IC para que os profissionais disponham de informações sobre as alternativas disponíveis para lhes oferecer.

As principais limitações deste estudo merecem ser observadas. As variáveis clínicas deste estudo ficaram limitadas a variáveis predominantemente físicas. Os estudos sobre variáveis preditoras do sono 
sugerem que aspectos psicossociais, como por exemplo, depressão e ansiedade, têm influência importante na qualidade do sono. Uma das principais limitações deste estudo foi a impossibilidade de incluir a aplicação do Inventário de Depressão de Beck.

O fato de a amostra deste estudo não ter sido aleatória, ser de um único serviço público especializado e de pacientes ambulatoriais limita a aplicação dos resultados a outros grupos. Essas características podem ter limitado a possibilidade de expressão de variáveis. A média de escolaridade pode ter se concentrado em valores que não representam a população brasileira de IC e a sua baixa amplitude pode não ter permitido identificar possível influência da escolaridade na qualidade do sono. Por a amostra ser de pacientes ambulatoriais, gravidades mais elevadas da IC foram pouco representadas. Amostras com maior proporção de pacientes com CF III e CF IV poderiam mostrar outros resultados de associação entre as variáveis.

O padrão de sono neste estudo foi avaliado por auto-relato, e não houve validação por medidas mais objetivas como a polissonografia. Podem existir diferenças em dados do padrão do sono obtidos por auto-relato e laboratoriais. No entanto, o interesse neste estudo era avaliar a qualidade subjetiva do sono.

Este estudo teve delineamento transversal, o que impede que se avalie a influência das variáveis ao longo do tempo. Estudos longitudinais são necessários para investigar possíveis fatores de risco para padrão de sono ruim.

Não encontramos até o término do preparo deste relatório, outro estudo sobre o sono em pacientes brasileiros com IC. Este estudo é, portanto, o primeiro sobre o padrão de sono de pacientes com IC no Brasil. Levando-se em conta a alta prevalência da IC, os resultados deste estudo podem facilitar o planejamento e desenvolvimento de ações que tenham impacto positivo no sono desses pacientes. 
Referências 


\section{REFERÊNCIAS}

Ahmed A, Allman RM, Aronow WS, Delong JF. Diagnosis of heart failure in older adults: predictive value of dyspnea at rest. Arch Gerontol Geriatr. 2004; 38(3):297-07.

Albanesi Filho FM. What is the current scenario for heart failure in Brazil?. Arq Bras Cardiol. 2005; 85(3):155-6.

Alebiosu OC, Ogunsemi OO, Familoni OB, Adebayo PB, Ayodele OE. Quality of sleep among hypertensive patients in a semi-urban Nigerian community: a prospective study. Postgrad Med. 2009; 121(1):166-72.

Associação Brasileira para o Estudo de Obesidade e da Síndrome Metabólica (ABESO) [internet]. São Paulo, 2009. [atualizado 2009 jan; citado 2010 abr.25]. Disponível em: http://www.abeso.org.br.

Bacal $F$, Silva CP. Análise Farmacocinética do tratamento da insuficiência cardíaca congestiva. Ed. Diagrafic.2007;(6):4-9.

Belza BL, Henke CJ, Yelin EH, Epstein WV, Gilliss CL. Correlates of fatigue in older adults with rheumatoid arthritis. Nurs Res 1993; 42(2):93-9.

Bertolazzi AN. Tradução, adaptação cultural e validação de dois instrumentos de avaliação do sono: Escala de sonolência de Epworth e Índice de qualidade de sono de Pittsburgh [tese]. Porto Alegre: Faculdade de Medicina, Universidade Federal do Rio Grande do Sul, 2008.

Bocchi EA, Guimarães G, Tarasoutshi F, Spina G, Mangini S, Bacal F. Cardiomyopathy, adult valve disease, and heart failure in South America. Heart. 2008; [Epub ahead of prin].

Braunwald E. Tratado de Medicina Cardiovascular. 5a ed. São Paulo: Roca; 1999. Capitulo 13, Fisiopatologia da Insuficiência Cardíaca. vol 1.

Bronstrom A, Stramberg A, Dahlstram U, Fridlund B. Congestive heart failure, spouses support and the couple's sleep situation: critical incident technique analysis. J Clin Nurs. 2003; 12(2):223-33.

Bronstrom A, Stroberg A, Dahlstrom U, Fridlund B. Patients with congestive heart failure and their conceptions of their sleep situation. J Adv Nurs. 2001; 34(4):520-29.

Bronstrom A, Stromberg A, Dahlstrom U, Fridlund B, Israelsson BV. Sleep difficulties, daytime sleepiness and health-related quality of life in patients with chronic heart failure. J Cardiovasc Nurs. 2004; 19(4):234-42. 
Buysse DJ, Reynolds CF, Monk TH, Berman SR, Hupfer DJ. The Pittsburg Sleep Quality Index: a new instrument for psychiatric practice and research. Psychiatry Res. 1989; 28:193-213.

Ceolim MF, Corrêa K. Qualidade do sono em pacientes idosos com patologias vasculares periféricas. Rev Esc Enferm USP. 2008; 42(1):12-8.

Chellapa SL, Araújo JF. Excessive daytime sleepiness in patients with depressive disorder. Rev Bras Psiquiatr. 2006; 28(2):126-29.

Chellapa SL, Araújo JF. Qualidade subjetiva do sono em pacientes com transtorno depressive. Estudos de Psicologia (Natal). 2007;12(3).

Chen HM, Clark AP, Tsai LM, Chao YFC. Self-reported sleep disturbance of patients with heart failure in Taiwan. Nurs Res. 2009; 58(1):63-71.

Chen HM, Clark AP. Sleep disturbances in people living with heart failure. J Cardiovasc Nurs. 2007; 22(3):177-85.

Colten HR, Altevogt BM. Institute of Medicine Committee on Sleep Medicine and Research. Sleep disorders and sleep deprivation: an unmet public health problem. Washington, DC: Institute of Medicine,National Academies Press; 2006.

Conard MW, Haddock CK, Poston WS, Spertus JA. The impact of smoking status on the health status of heart failure patients. Congest Heart Fail. 2009; 15(2):82-6.

Costa DD, Bernatsky S, Dritsa M. Determinants of sleep quality in women with systemic lupus erythematosus. Arthritis Rheum. 2005; 53(2):272-78.

Crosby LJ. Factors which contribute to fatigue associated with rheumatoid arthritis. J Adv Nurs. 1991; 16(8):974-981.

Curiati JA, Bocchi EA, Freire JO, Arantes AC, Braga M, et al.Medication reduces sympathetic activation and improves the quality of life in elderly patients with optimally treated heart failure: a prospective randomized study. J Altern Complement Med. 2005; 11:465-72.

Doi Y, Minowa M, Uchiyama M, Okawa M. Subjective sleep quality and sleep problems in the general Japanese adult population. Psychiatry Clin Neurosci. 2001; 55:213-15.

Ekman I, Cleland K, Charlesworth A, Metra M, Poole-Wilson PA. Symptoms in patients with heart failure are prognostic predictors. J Card Fail. 2005; 11(4):288-92.

Erickson VS, Westlake CA, Dracup KA, Woo M, Hage A. Sleep disturbance symptoms in patients with heart failure. AACN Clin Issues. 2003; 14(4):47787. 
Eryilmaz MM, Ozdemir C, Yurtman F, Cilli A, Karaman T. Quality of sleep and quality of life in renal transplantation patients. Transplant Proc. 2005; 37(5):2072-6.

Fávero LP, Beltfiore P, Silva FL, Chan BL. Análise de dados - Modelagem multivariada para tomada de decisões. Rio de Janeiro: Elsevier; 2009.

Fini A. Cracterísticas da fadiga em pacientes com insuficiência cardíaca [dissertação]. São Paulo: Escola de Enfermagem, Universidade de São Paulo; 2008.

Freedland KE, Carney RM. Psychosocial considerations in elderly patients with heart failure. Clin Geriatr Med. 2000; 16:649-61.

Friedman J, Friedman H. Fatigue in older women with heart failure. 1993. Abstract at the American Heart Association's $66^{\text {th }}$ Scientific sessions. USA, Atlanta, GA.

Gorestein C, Andrade L. Validation of a Portuguese version of the Beck Depression Inventory and the State-Trait Anxiety Inventory in Brazilian subjects. Braz J Med Biol Res. 1996; 29(4):453-57.

Grandner MA, Patel NP, Gehrman PR, Xie D, et al. Who gets the best sleep? Ethnic socioeconomic factors related to sleep complaints. Sleep Med. 2010; 11:470-78.

Guimarães GV, Bellotti G, Wajngarten M, Teixeira L, Ramires JF, Bocchi EA, Exercício e Insuficiência Cardíaca: Estudo da relação da gravidade da doença com o limiar anaeróbico e o ponto de compensação respiratório. Arq Bras Cardiol. 1999; 73(4):339-43.

Hagenah G, Beil D. Prevalence of Cheyne-Stokes respiration in modern treated congestive heart failure. Sleep Breath. 2009; 13:181-85.

Hanly PJ, Zuberi-Khokhar N. Daytime sleepiness in patients with congestive heart failure and Cheyne-Stokes respiration. Chest. 1995; 107(4):952-8.

Hanly PJ, Zuberi-Khokhar N. Periodic limb movements during sleep in patients with congestive heart failure. Chest. 1996; 109(6):1497-502.

Hayes DJ, Anstead MI, Ho J, Phillips BA. Insomnia and heart failure. Heart Fail Rev. 2009; 14(3):171-82.

Iliescu EA, Coo H, McMurray MH, Meers CL, Quinn MM, Singer MA, Hopman WM. Quality of sleep and health-realted quality of life in haemodialysis patients. Nephrol Dial Transplant. 2003; 18(1):126-32. 
International Physical Activity Questionnarie (IPAQ). Centro CoordenadorBrasil. Classificação do nível de atividade física - IPAQ 2007 [texto na internet]. São Caetano do Sul; 2010 [citado 2010 abr.25]. Disponível em: http://www.celafiscs.institucional.ws/65/questionarios.html.

Jaehne A, Loessi B, Bárkai Z, Riemann D, Hornyah M. Effects of nicotine on sleep during consumption, withdrawal and replacement therapy. Sleep Med Rev. 2009; 13(5):363-77.

Joahansson $\mathrm{P}$, Dalhlstrom $\mathrm{U}$, Brostrom $\mathrm{A}$. Factors and interventions influencing health-related quality of life in patients with heart failure: A review of the literature. Eur J Cardiovasc Nurs. 2006; (5):5-15.

Krachman SL, D'Alonzo GE, Berger TJ, Eisen HJ. Comparision of oxygen therapy with nasal continuous positive airway ressure on cheyne-stokes respiration during sleep in congestive heart failure. Chest. 1999; 116(6):1550-7.

Lauderdale DS, Knutson KL, Yan LL, Rathouz PJ, Hulley SB, Siney S, et al. Objectively measured sleep characteristics among early-middle-aged adults: The Cardia study. Am J Epidemiol.2006; 164(1):5-16.

Leegte-Lesman I, Jaarsma T, Sanderman R, Hillege HL, Velldhuisen DJ. Determinants of depressive symptoms in hospitalized men and women with heart failure. Eur J Cardiovasc Nurs. 2008; 7:121-26.

Lloyd-Jones D, Adams R, Carnethon M, De Simone G, Ferguson TB, Flegal $\mathrm{K}$, et al. Heart Disease and Stroke Statistics-2009 Update. A report from the American Heart Association Statistics Committee and Stroke Statistics Subcommittee. Circulation. 2009; 119(3):e21-181.

Mahfoud Y, Talih F, Streem D, Budur K. Sleep disorders in substance abusers: how common are they?. Psychiatry. 2009; 6(9):38-42.

Mahler DA, Weinberg DH, Wells CK, Feinstein AR. The measurement of dyspnea - Contentes, interobserver agreement and physiologic correlates of two new clinical indexes. Chest. 1984; 85:751-8.

Manochia M, Keller S, Ware JE. Sleep problems, health-related quality life, work functioning and health care utilization among the chronically ill. Qual Life Res. 2001; (10): 331-45.

Martin-Pfitzenmeyer I, Gauthier S, Bailly M, Loi N, et al. Prognostic factors in stage D heart failure in the very elderly. Gerontology. 2009; 55(6):719-26.

Matsudo SSM, Araújo T, Matsudo VKR, Andrade D, Andrade E, Oliveira LC, et al. Questionário Internacional de Atividade Física (IPAQ): estudo de validade e reprodutividade do Brasil. Rev Bras Ativ Fís Saúde. 2001; 6:5-18. 
Merlino G, Fratticci L, Lenchig C, Valente $M$, Cargnelutti D, Picello $M$, Serafini A, Dolso P, Gigli GL. Prevalence of "poor sleep" among patients with multiple sclerosis: an independent predictor of mental and physical status. Sleep Med. 2009; 10(1):26-34.

Meyers LS, Gamst G, Guarino AJ. Applied Multivariate Research: design and interpretation. Califórnia: Sage Publications; 2006.

Midgren B, Mared L, Franklin KA, Berg S, Erhardt L, Cline C. Cheyne-Stokes respiration is not related to quality of life or sleepiness in heart failure. Clin Respir J. 2010; 4(1):30-6.

Miller-Davis C, Marden S, Leidy NK. The New York Heart Association Classes an functional status: What are we really measuring? Heart Lung. 2006; 35(4):217-24.

Mystakidou K, Parpa E, Tsilika E, Pathiaki M, Gennatas K, Smyrniotis V, Vassiliou I. The relationship of subjective sleep quality, pain and quality of life in advanced cance patients. Sleep. 2007; 30(6):737-42.

NANDA (North American Diagnosis Association). Diagnósticos de enfermagem da NANDA: definições e classificações 2009-2011/NANDA Internacional; Trad Regina Machado Garcez. Porto Alegre: Artmed, 2010.

National Sleep Foundation. 2005 Sleep in America Poll. Washington(DC): National Sleep Foundation; 2005.

Niebauer J, Clark AL, Webb-Peploe KM, Böger R, Coats AJ. Home-based exercise training modulates pro-oxidant substrates in patients with chronic heart failure. Eur J Heart Fail. 2005;7:183-8.

Paparrigopoulos T, Tzavara C, Theleritis C, Soldatos C, Tountas Y. Physical activity may promote sleep in cardiac patients suffering from insomnia. Int $\mathrm{J}$ Cardiol. 2008 Dec 22; [Epud ahead of print].

Pasquali L. Psicometria : Teoria dos testes na Psicologia e na Educação. Petrópolis(RJ): Vozes; 2003.

Paulino A, Damy T, Margarit L, Stoïca M, Deswarte G, Khouri L, et al. Prevalence of sleep-disordered breathing in a 316-patient French cohort of stable congestive heart failure. Arch Cardiovasc Dis. 2009; 102(3):169-75.

Pereira JCR. Análise de dados qualitativos. São Paulo:EDUSP; 1999.

Phillips B. Sleep-disordered breathing and cardiovascular disease. Sleep Med Rev. 2005; (9):131-40.

Príncipe-Rodriguez K, Strohl KP, Hadziefendic S, Pina IL. Sleep symptoms and clinical markers of illness in patients with heart failure. Sleep Breath. 2005; 9(3):127-33. 
Pullen PR, Nagamia SH, Mehta PK, Thompson WR, Benardot D, Hammoud $E$, et al. Effects of yoga on inflammation and exercise capacity in patients with chronic heart failure. J Card Fail. 2008; 14:407-13.

Qureshi A, Lee-Chiong TJ. Medications and their effects on sleep. Med Clin North Am. 2004;88(3):751-66.

Ramasamy R, Hildebrandt T, O'Hea E, Patel M, Clemow L, Freudenberger $\mathrm{R}$, et al. Psychological and social factors that correlate with dyspnea in heart failure. Psychological. 2006; 47(5):430-4.

Ranjbaran Z, Keefer L, Farhadi A, Stepanski E, Sedghi S, Kesharvarzian A. Impact of sleep disturbances in inflammatory bowel disease. J Gastroenterol Hepatol. 2007; 22(11):1748-53.

Rausch SM, Baker K, Boonmee J. Sleep disturbances in caregivers of patients with end-stage congestive heart failure: Part II - assess and intervene. Prog Cardiovasc Nurs. 2007; 22(2):93-6.

Redeker NS, Hilkert R. Quality of life in stable heart failure. J Card Fail. 2005; 11(9):700-5.

Redeker NS. Sleep disturbance in people with heart failure: implications for self-care. J Cardiovasc Nurs. 2008; 23(3):231-8.

Redeker NS, Muench U, Zucker MJ, Walsleben J, Gilbert M, et al. Sleep disordered breathing, daytime symptoms, and functional performance in stable heart failure. Sleep. 2010; 33(4):551-60.

Redeker NS, Stein S. Characteristics of sleep in patients with stable heart failure versus a comparison group. Heart Lung. 2006; 35(4):252-61.

Remme WJ, Swedberg K. Guidelines for the diagnosis and treatment of chronic heart failure. Eur Heart J. 2001; 22(17):1527-60.

Riegel B, Weaver TE. Poor sleep and impaired self-care: Towards a comprehensive model linking sleep, cognition and heart failure outcomes. Eur J Cardiovasc Nurs. 2009; (8):337-44.

Riegger GA, Bouzo $H$, Peter $P$, Munz J, Spacek $R$, Pethig $H$, et al. Improvement in exercise tolerance and symptoms of congestive heart failure during treatment with Candesartan Cilexetil. Circulation. 1999; 100(22):222430 .

Rosenblatt PC. Two in a bed: the social system of couple bed-sharing. Albany(NY): University of New York Press; 2006. 
Sá PF. Estudo do sono, espirometria e manovacuometria em pacientes portadores de insuficiência cardíaca congestiva classe funcional II e III [dissertação]. São José dos Campos: Universidade do Vale do Paraíba; 2006.

Sabattini M, Crispo A, Gallo A. Sleep quality in renal transplant patients: a never investigated problem. Nephrol Dial Transplant. 2005; 20(1):194-98.

Sahlin C, Franklin KA, Stenlund H, Lindberg E. Sleep in women: Normal values for sleep stages and position and the effect of age, obesity, sleep apnea, smoking, alcohol and hypertension. Sleep Med. 2009; 10(9):1025-30.

Santos JJA, Plewka JEA, Brofman PRS. Quality of life and clinical indicators in heart failure: A multivariate analysis. Arq Bras Cardiol. 2009; 93(2):159166.

Sassanabe R, Shiomi T. Heart failure. Nippon Rinsho. 2009; 67(8):1513-7.

Sayar K, Arikan M, Yontem T. Sleep quality in chronic pain patients. Can J Psychiatry. 2002; 47(9):844-48.

Schmid JP, Noveanu M, Morger C, Gaillet R, Capoferri M, Anderegg M, et al. Influence of water immersion, water gymnastics and swimming on cardiac output in patients with heart failure. Heart. 2007; 93:722-7.

Schulz R, Blau A, Borgel J, Duchna HW, Fietze I, Koper I, et al. Sleep apnoea in heart failure. Eur Respir J. 2007; 29(6):1201-5.

Siegel S, Castellan NJJ. Estatística não-paramétrica para ciências do comportamento. 2a ed. Porto Alegre: Artmed, 2006.

Silva RS. Prevalência de distúrbios respiratórios do sono em pacientes ambulatórias com insuficiência cardíaca [tese]. São Paulo: Faculdade de Medicina, Universidade de São Paulo; 2004.

Skobel E, Norra C, Sinhá A, Breuer C, Hanath P, Stellbrink C. Impact of sleep-related breathing disorders on health-related quality of life in patients with chronic heart failure. Eur J Heart Fail. 2005; (7):505-11.

Sociedade Brasileira de Cardiologia. III Diretriz Brasileira de Insuficiência Cardíaca Crônica. Arq Bras Cardiol. 2009;93(1 Suppl 1):1-71.

Soll BA, Yeo KK, Davis JW, Seto TB, Schatz IJ, Shen EN. The effect of posture on Cheyne-Stokes respirations and hemodynamics in patients with heart failure. Sleep. 2009;32(11):1499-506.

Sousa AGP, Mancini CCC, Halpern A. Síndrome da apnéia-hipopnéia obstrutiva do sono: uma complicação da obesidade frequentemente esquecida. Rev ABESO. 2008; 36(36):2-6. 
Staniforth Ad, Kinnear WJ, Starling R, Hetmanski DJ, Cowley AJ. Effect of oxygen on sleep quality, congnitive function and sympathetic activity in patients with chronic heart failure and cheyne-stokes respiration. Eur Heart J. 1998; 19(6):922-8.

Steens RD, Millar TW, Su X, Biberdorf D, Buckle P, Ahmed M, Kryger MH. Effect of inhaled $\mathrm{CO} 2$ on Cheyne-Stokes respiration in congestive heart failure. Sleep. 1994; 17(1):61-8.

Tiesinga LJ, Dassen TW, Halfens RJ. DUFS and DEFS: Development, reliability and validity of the Dutch Fatigue Scale and the Dutch Exertion Fatigue Scale. Int J Nurs Stud. 1998; 35:115-23.

Trouxel WM, Robles TF, Hall M, Buysse DJ. Marital quality and the marital bed: examining the covariation between relationship quality and sleep. Sleep Med Rev. 2007; 11:389-404.

Tsai CF, Ouyang WC, Tsai SJ, Hong CJ, Lin TL. Risk factors for poor sleep quality among patients with interstitial cystitis in Taiwan. Neurourol Urodyn. 2009 Nov 6; [Epud ahead of print].

Uchiyama LN. Estudo da dessaturação de oxigênio durante o sono em pacientes portadores de insuficiência cardíaca classe II e III [dissertação]. São José dos Campos: Universidade do vale do Paraíba; 2005.

Uren NG, Lipkin DP. Exercise training as therapy for chronic heart failure. $\mathrm{Br}$ Heart J. 1992;67:430-33.

Valdini AF, Steinhardt SI, Jaffe AS. Demographic correlates of fatigue in a university family health centre. Fam Pract. 1987; 4(2):103-7.

Van Diest R, Apples A. Vital exhaustion and depression: A conceptual study. J Psychosom Res. 1991; 35:535-44.

Vieira, S. Bioestatística-Tópicos Avançados. Rio de Janeiro: Campus; 2003.

Whitney CW, Enright PL, Newman AB, Bonekat W, Foley D, Quan SF. Correlates of daytime sleepness en 4578 elderly persons: the Cardiovascular Health Study. Sleep. 1998; 21(1):27-36.

Wisloff U, StØylen A, Loennechen JP, Bruvold M, Rognm $\varnothing$, Haram PM, et al. Superior cardiovascular effect of aerobic interval training versus moderate continuous training in heart failure patients: a ramdomized study. Circulation. 2007; 115:3086-94.

Yamazaki T, Asanoi H, Ueno H, Yamada K, Takagawa J, Kameyama T, Hirai T, Ishizaka S, Nozawa T, Inoue H. Central sympathetic inhibition augments sleep-related ultradian rhythm of parasympathetic tone in patients with chronic heart failure. Circulation. 2005; 69(9):1052-6. 
Yeh GY, Mietus JE, Peg CK, Phillips RS, Davis RB, Wayne PM, Goldberg AL, Thomas RJ. Enhancement of sleep stability with Tai Chi exercise in chronic heart failure: preliminary findings using an ECG-based spectrogram method. Sleep Med. 2008; 9(5):527-36.

Yeh GY, Wood MJ, Lorell BH, Stevenson LW, Eisenberg DM, Wayne PM, et al. Effects of tai chi mind-body movement therapy on functional status and exercise capacity in patients with chronic heart failure: a randomized controlled trial. Am J Med. 2004; 117:541-8.

Yilmaz MB, Erdem A, Yalta K, Turgut OO, Yilmaz A, Tandogan I. Impacto of beta-blockers on sleep in patients with hypertension: a randomized trial between nebivolol and metropolol. Adv Ther. 2008; 25(9):871-83.

Yuksel $H$, Sogut A, Yilmaz O, Demet M, ERgin D, Kirmaz C. Evalution of sleep quality and anxiety-depression parameters in asmatic children and their mothers. Respir Med. 2007; 101(12):2550-4.

Yumino D, Wang H, Floras JS, Newton GE, Mak S, Ruttanaumpawan P, et al. Prevalence and physiological predictors of sleep apnea in patients with heart failure and systolic dysfunction. J Card Fail, 2009; 15(4):279-85.

Zambroski CH, Moser DK, Bhat G, Ziegler C. Impact of symptom prevalence and symptom burden on quality of life in patients with heart failure. Eur $\mathrm{J}$ Cardiovasc Nurs. 2005; 4(3):198-201.

Zaslavsky C, Gus I. Idoso. Doença cardíaca e comorbidades. Arq Bras Cardiol. 2002;79(6):635-9.

Zeitlhofer J, Seidel S, Klösch G, Moser D, Anderer P, et al. Sleep habits and sleep complains in Austria: current self-reported data on sleep behavior, sleep disturbances and their treatment. Acta Neurol Scand. [In press 2010].

Zilberman M, Silverberg DS, Bits I, Steinbruch S, Wexler D, Sheps D, Schwartz D, Oksenberg A. Improvement of anemia with erythropoietin and intravenous iron reduces sleep-related breathing disorders and improves daytime sleepiness in anemic patients with congestive heart failure. Am Heart J. 2007; 154(5):870-6.

Zisapel N. Sleep and sleep disturbances: biological basis and clinical implications. Cell Mol Life Sci. 2007;64:1174-86. 


\section{Apêndices}




\section{APÊNDICE I}

Número do Instrumento:

\section{Parte A - Caracterização social e clínica}

Data da coleta dos dados: CF: $\square$ I $\square$ II $\square$ III $\square$ IV

Nome:

RG:

Telefone de contato: Peso: Altura:

Sexo: $1 \square$ Masculino $2 \square$ Feminino Idade: anos

Escolaridade: anos

Ocupação atual:

Convivência marital: $1 \square \operatorname{Sim} 2 \square$ Não

Diagnóstico médico principal (motivo pelo qual é acompanhado no serviço):

Outras doenças:

$1 \square$ HAS

$2 \square$ Diabetes melitus

$3 \square$ Doenças respiratórias

$4 \square$ Doenças infecciosas

$5 \square$ Doença nas articulações

$6 \square$ Câncer

$7 \square$ Outras 


\section{Parte B - Avaliação do Sono, Fadiga e Depressão}

\section{ÍNDICE DE QUALIDADE DE SONO DE PITTSBURGH (PSQI-BR)}

Instruções:

As seguintes perguntas são relativas aos seus hábitos de sono durante o último mês somente. Suas respostas devem indicar a lembrança mais exata da maioria dos dias e noites do último mês. Por favor, responda a todas as perguntas.

1. Durante o último mês, quando você geralmente foi para a cama à noite? Hora usual de deitar:

2. Durante o último mês, quanto tempo (em minutos) você geralmente levou para dormir à noite?

Número em minutos:

3. Durante o último mês, quando você geralmente levantou de manhã? Hora usual de levantar:

4. Durante o último mês, quantas horas de sono você teve por noite? (Este pode ser diferente do número de horas que você ficou na cama).

Horas de sono por noite:

Para cada uma das questões restantes, marque a melhor (uma) resposta. Por favor, responda a todas as questões.

5. Durante o último mês, com que freqüência você teve dificuldade de dormir porque você...

(a) Não conseguiu adormecer em até 30 minutos

$\square$ Nenhuma no último mês

$\square$ Menos de 1 vez/semana

$\square 1$ ou 2 vezes/semana

$\square 3$ ou mais vezes/semana

(b) Acordou no meio da noite ou de manhã cedo
$\square$ Nenhuma no último mês
$\square$ Menos de 1 vez/semana
$\square 1$ ou 2 vezes/semana
$\square 3$ ou mais vezes/semana

(c) Precisou levantar para ir ao banheiro

$\square$ Nenhuma no último mês

Menos de $1 \mathrm{vez} / \mathrm{semana}$

$\square 1$ ou 2 vezes/semana

3 ou mais vezes/semana

(d) Não conseguiu respirar confortavelmente

$\square$ Nenhuma no último mês

$\square$ Menos de 1 vez/semana

$\square 1$ ou 2 vezes/semana

3 ou mais vezes/semana 
(e) Tossiu ou roncou forte

$\square$ Nenhuma no último mês

$\square 1$ ou 2 vezes/semana

(f) Sentiu muito frio

$\square$ Nenhuma no último mês

1 ou 2 vezes/semana

(g) Sentiu muito calor

$\square$ Nenhuma no último mês

$\square 1$ ou 2 vezes/semana

(h) Teve sonhos ruins

$\square$ Nenhuma no último mês

$\square 1$ ou 2 vezes/semana

(i) Teve dor

$\square$ Nenhuma no último mês

$\square 1$ ou 2 vezes/semana
Menos de $1 \mathrm{vez} / \mathrm{semana}$

3 ou mais vezes/semana

Menos de $1 \mathrm{vez} / \mathrm{semana}$

3 ou mais vezes/semana

Menos de 1 vez/semana

3 ou mais vezes/semana

Menos de 1 vez/semana

3 ou mais vezes/semana

Menos de 1 vez/semana

3 ou mais vezes/semana

(j) Outra(s) razão(ões), por favor descreva

Com que freqüência, durante o último mês, você teve dificuldade para dormir devido a essa razão?

$\square$ Nenhuma no último mês

Menos de 1 vez/semana

$\square 1$ ou 2 vezes/semana

3 ou mais vezes/semana

6. Durante o último mês, como você classificaria a qualidade do seu sono de uma maneira geral?

Muito boa

Boa $\square$

Ruim

Muito ruim

7. Durante o último mês, com que freqüência você tomou medicamento (prescrito ou "por conta própria") para lhe ajudar a dormir?

$\square$ Nenhuma no último mês

$\square$ Menos de 1 vez/semana

$\square 1$ ou 2 vezes/semana

3 ou mais vezes/semana

8. No último mês, com que freqüência você teve dificuldade de ficar acordado enquanto dirigia, comia ou participava de uma atividade social (festa, reunião de amigos, trabalho, estudo)?

$\square$ Nenhuma no último mês

$\square$ Menos de 1 vez/semana

$\square 1$ ou 2 vezes/semana

3 ou mais vezes/semana 
9. Durante o último mês, quão problemático foi para você manter o entusiasmo (ânimo) para fazer as coisas (suas atividades habituais)?

Nenhuma dificuldade

Um problema leve

Um problema razoável

Um grande problema

10. Você tem um(a) parceiro(a) ou colega de quarto?

Não $\square$

Parceiro ou colega, mas em outro quarto

Parceiro no mesmo quarto, mas não na mesma cama

Parceiro na mesma cama

Se você tem um parceiro ou colega de quarto, pergunte a ele/ela com que freqüência, no último mês, você teve...

(a) Ronco forte

$\square$ Nenhuma no último mês

$\square 1$ ou 2 vezes/semana

Menos de $1 \mathrm{vez} / \mathrm{semana}$

3 ou mais vezes/semana

(b) Longas paradas na respiração enquanto dormia

$\square$ Nenhuma no último mês $\square$ Menos de 1 vez/semana

$\square 1$ ou 2 vezes/semana $\quad \square 3$ ou mais vezes/semana

(c) Contrações ou puxões nas pernas enquanto você dormia

$\square$ Nenhuma no último mês $\square$ Menos de 1 vez/semana

$\square 1$ ou 2 vezes/semana $\quad \square 3$ ou mais vezes/semana

(d) Episódios de desorientação ou confusão durante o sono
$\square$ Nenhuma no último mês
$\square$ Menos de 1 vez/semana
$\square 1$ ou 2 vezes/semana
$\square 3$ ou mais vezes/semana

(e) Outras alterações (inquietações) enquanto você dorme, por favor, descreva

$\begin{array}{ll}\square \text { Nenhuma no último mês } & \square \text { Menos de } 1 \text { vez/semana } \\ \square 1 \text { ou } 2 \text { vezes/semana } & \square \text { ou mais vezes/semana }\end{array}$




\section{DUFS - Auto Relato}

Os sintomas da fadiga estão descritos na próxima página. Pedimos que você indique 0 quanto você apresenta de cada um desses sintomas. Marque um $\mathrm{X}$ em um dos cinco quadradinhos entre não e sim, sendo que o não significa que esta situação não ocorre com você e o sim significa que a situação ocorre sempre. Por favor, não deixe de responder sobre nenhum sintoma.

Abaixo há dois exemplos que Ihe darão uma idéia de como responder às questões. Em quase todas as questões o aparece o termo ultimamente; ele se refere aos últimos $\mathbf{3}$ a 6 meses.

\section{Exemplos}

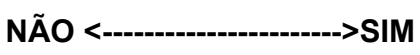

Ultimamente, você tem dito para si mesmo(a) que as coisas não são tão ruins ?

\section{区}

[Se, por exemplo, tem sido raro você dizer isso para si mesmo(a) ultimamente, marque o segundo quadradinho da esquerda para a direita]

Ultimamente, você tem evitado situações difíceis?

[Se, por exemplo, você sempre evita situações difíceis, marque o quadradinho da extrema direita]

\section{NÃO <--_---osIM}

1 Ultimamente você tido uma sensação forte e constante de falta de energia?

2 Ultimamente você tem observado que precisa de mais energia para dar conta das suas tarefas diárias?

3 Ultimamente você tem se sentido sem disposição para fazer as coisas?

4 Ultimamente você tem acordado com a sensação de estar exausto e desgastado?

$5 \quad$ Ultimamente você tem tido necessidade de descansar mais?

6 Ultimamente você tem conseguido fazer suas atividades do diaa-dia?

7 Ultimamente seu interesse por sexo, sua vontade de ter relações sexuais diminuiu?

8 Tem sido mais difícil se concentrar em uma coisa por muito tempo? 


\section{DEFS - Auto Relato}

Na próxima página são listadas várias atividades do dia-a-dia. Pedimos que você descreva o quanto essas atividades são atualmente fatigantes para você. Marque um $\mathrm{X}$ em um dos cinco quadradinhos entre não e sim, sendo que o não significa que a atividade não lhe causa fadiga e o sim significa que essa atividade é extremamente fatigante. Por favor, não deixe de responder nenhuma questão.

Abaixo há dois exemplos que dão uma idéia de como responder as questões.

\section{Exemplos:}

Você acha fatigante preparar sanduíches?<smiles>[Mg][AsH]O[W]</smiles>

[Se, por exemplo, você acha que essa atividade é só um pouco fatigante, marque o segundo quadradinho.]

Você acha fatigante por e tirar a roupa?

$\bigotimes$

[Se, por exemplo, você acha que essa atividade é extremamente fatigante, marque o quadradinho da extrema direita]

1 Você acha fatigante caminhar por 10 minutos?

2 Você acha fatigante caminhar por meia hora?

3 Você acha fatigante ficar em pé embaixo do chuveiro?

$4 \quad$ Você acha fatigante subir e descer escadas?

$5 \quad$ Você acha fatigante sair para comprar alguma coisa?

6 Você acha fatigante recolher o lixo da casa?

7 Você acha fatigante passar o aspirador na casa?

8 Você acha que visitar outras pessoas, em geral, é fatigante?

9 Você acha fatigante participar de encontros sociais especiais, como uma festa de aniversário?

NÀO

凶 SIM 


\section{QUESTIONÁRIO INTERNACIONAL DE ATIVIDADE FÍSICA}

Instruções:

As perguntas estão relacionadas ao tempo que você gasta fazendo atividade física na ÚLTIMA semana. Pense somente nas atividades que você realiza por pelo menos $\underline{10}$ minutos contínuos da cada vez.

Para responder as questões lembre que:

- atividades físicas VIGOROSAS são aquelas que precisam de um grande esforço físico e que fazem respirar MUITO mais forte que o normal.

- atividades físicas MODERADAS são aquelas que precisam de algum esforço físico e que fazem respirar UM POUCO mais forte que o normal.

1a. Em quantos dias da última semana você CAMINHOU por pelo menos 10 minutos contínuos em casa ou no trabalho, como forma de transporte, por lazer ou como forma de exercício?

Dias___por SEMANA ( ) nenhum

1b. Nos dias em que você caminhou, quanto tempo no total você gastou caminhado por dia?

Horas:___ Minutos:

2a. Em quantos dias da última semana, você realizou atividades MODERADAS por pelo menos 10 minutos contínuos, como por exemplo, pedalar leve na bicicleta, dançar, carregar pesos leves, varrer, aspirar, cuidar do jardim, atividade que fez aumentar moderadamente sua respiração ou batimentos do coração (POR FAVOR NÃO INCLUA CAMINHADA)

Dias por SEMANA ( ) nenhum 
Mariana Alvina dos Santos

2b. Nos dias em que você fez essas atividades moderadas, quanto tempo no total você gastou fazendo essas atividades por dia?

Horas: Minutos:

3a. Em quantos dias da última semana, você realizou atividades VIGOROSAS por pelo menos 10 minutos contínuos, como por exemplo correr, fazer ginástica aeróbica, jogar futebol, pedalar rápido na bicicleta, carregar pesos elevados, atividades que fez aumentar MUITO sua respiração ou batimentos do coração.

Dias por SEMANA ( ) nenhum

3b. Nos dias em que você fez essas atividades vigorosas quanto tempo no total você gastou fazendo essas atividades por dia?

Horas: Minutos:

Essas últimas questões são sobre o tempo que você permanece sentado todo dia, no trabalho, na escola ou faculdade, em casa e durante seu tempo livre. Isto inclui o tempo sentado estudando, sentado enquanto descansa, visitando um amigo, lendo, assistindo TV. Não inclua o tempo gasto sentado durante o transporte em ônibus, trem, metrô ou carro.

4a. Quanto tempo no total você gasta sentado durante um dia de semana?

Horas: Minutos:

4b. Quanto tempo você gasta sentado durante em um dia de final de semana?

Horas: Minutos: 


\section{Terapia Medicamentosa}

\begin{tabular}{|l|l|l|l|}
\hline $\begin{array}{l}\text { Quais medicamentos o } \\
\text { Sr(a) usou nos últimos 15 } \\
\text { dias? }\end{array}$ & $\begin{array}{l}\text { Dosagens (dose, } n^{\circ} \\
\text { de tomadas por dia } \\
\text { e via) }\end{array}$ & $\begin{array}{l}\text { Há quanto tempo usa } \\
\text { cada medicamento? }\end{array}$ & $\begin{array}{l}\text { O Sr(a) usa o } \\
\text { medicamento conforme } \\
\text { foi prescrito? }\end{array}$ \\
\hline 1 & & & $1 \square \operatorname{sim} \quad 2 \square$ não \\
\hline 2 & & & $1 \square \operatorname{sim} \quad 2 \square$ não \\
\hline 3 & & & $1 \square \operatorname{sim} \quad 2 \square$ não \\
\hline 4 & & & $1 \square \operatorname{sim} 2 \square$ não \\
\hline 5 & & & $1 \square \operatorname{sim} \quad 2 \square$ não \\
\hline 6 & & & $1 \square \operatorname{sim} \quad 2 \square$ não \\
\hline 7 & & & $2 \square$ não \\
\hline
\end{tabular}

Observações sobre terapia medicamentosa:

\section{Dispnéia}

O Sr.(a) senta falta de ar?

$1 \square \operatorname{sim} \quad 2 \square$ não

Se sim, quando o $\operatorname{Sr}(a)$ sente falta de ar?

$\square$ pequenos esforços $\square$ médios esforços $\square$ grandes esforços $\square$ intensos esforços

\section{Hábito de fumar}

$\mathrm{O} \mathrm{Sr}(\mathrm{a})$ fuma atualmente?

$1 \square \operatorname{sim} \quad 2 \square$ não

Parou de fumar nos últimos 12 meses?

$1 \square \operatorname{sim} \quad 2 \square$ não 
Anexos 


\section{ANEXO}

\section{Parecer do comitê de Ética}

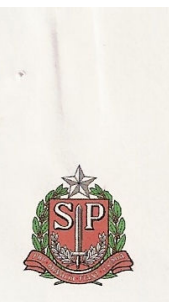

\section{SECRETARIA DE ESTADO DA SAÚDE \\ Coordenadoria de Serviços de Saúde \\ INSTITUTO DANTE PAZZANESE DE CARDIOLOGIA \\ Comitê de Ética em Pesquisa}

DATA DA ENTRADA: 27 de abril de 2009.

DATA DA AVALIAÇÃO: 12 de maio de 2009.

NN DO PROTOCOLO NO CEP: 3793

(este $n^{0}$ deverá citar nas correspondências referentes a este projeto)

Investigadora: Mariana Alvina dos Santos

Orientadora: Prof ${ }^{a}$ Dr $^{\mathrm{a}}$ Diná de Almeida L. Monteiro da Cruz

$N^{\circ}$ de Sujeitos no Centro: 384

$\mathbf{N}^{\circ}$ de Sujeitos no Brasil: 384

$\mathbf{N}^{\circ}$ de Sujeitos Total: 384

Área de Conhecimento: Ciências da Saúde - Enfermagem - Epide

Área Temática Especial: Não se aplica

Fase: Não se aplica

Duração do Estudo: 12 meses

Patrocinador: Não se aplica

Grupo: III

Projeto de Pesquisa: "Características do Sono de Pacientes com Insuficiência Cardíaca".

Considerações/Comentários: O objetivo deste estudo é descrever o padrão de sono em pacientes portadores de IC, associando padrão de sono e sexo, idade, fadiga, atividade física, classe funcional, terapia medicamentosa, depressão, dispnéia e IMC.

Ao se proceder à análise ao projeto em questão, considera-se que:

a) O projeto preenche os requisitos fundamentais das resoluções CNS 196/96, 251/97 e 292/99, sobre as Diretrizes e Normas Regulamentadoras de Pesquisa Envolvendo Seres Humanos, do Conselho Nacional de Saúde / 


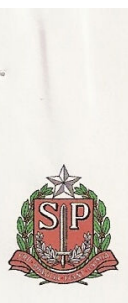

\section{SECRETARIA DE ESTADO DA SAÚDE \\ Coordenadoria de Serviços de Saúde INSTITUTO DANTE PAZZANESE DE CARDIOLOGIA \\ Comitê de Ética em Pesquisa}

Conselho Nacional de Ética em Pesquisa / Agência Nacional de Vigilância Sanitária e as Boas Práticas de Pesquisa Clínica do ICH-GCP.

b) O Comitê de Ética em Pesquisa avaliou o Protocolo de Estudo e o Termo de Consentimento Livre e Esclarecido.

c) O Comitê de Ética em Pesquisa segue os preceitos das resoluções CNS196/96, 251/97 e 292/99, sobre as Diretrizes e Normas Regulamentadoras de Pesquisa Envolvendo Seres Humanos, do Conselho Nacional de Saúde / Conselho Nacional de Ética em Pesquisa / Agência Nacional de Vigilância Sanitária e as Boas Práticas de Pesquisa Clínica do ICH-GCP.

\section{Diante do exposto, 0 Comitê de Ética em Pesquisa, manifesta-se pela:}

- Protocolo de Pesquisa Clínica - Aprovado

- Cronograma do Estudo - Entregue

- Folha de Rosto - Entregue

- Apêndice I - Parte A - Caracterização social e clínica - Aprovado

- Apêndice I - Parte B - Avaliação do Sono, Fadiga e Depressão Aprovado

- DUFS - Auto Relato - Entregue

- DEFS - Auto Relato - Entregue

- Inventário de Beck - Entregue

- Parte C - Avaliação da Atividade física, terapia medicamentosa e dispnéia - Questionário Internacional de Atividade Física - Entregue

- Termo de Consentimento Livre e Esclarecido - Aprovado

- Carta de Encaminhamento - Entregue

- Declaração de Realização do Estudo - Andréa Cotait Ayoub - Diretora da Divisão de Enfermagem - Entregue 


\section{SECRETARIA DE ESTADO DA SAÚDE \\ Coordenadoria de Serviços de Saúde INSTITUTO DANTE PAZZANESE DE CARDIOLOGIA \\ Comitê de Ética em Pesquisa}

- Declaração de Realização do Estudo - Luciana de Oliveira Bueno - Enfa Chefe da Seção de Enfermagem Ambulatorial - Entregue

- Declaração de Realização do Estudo - Dr.João Manoel Rossi - Chefe do Setor de Disfunção Ventricular - Entregue

- Declaração de Propriedade das Informações - Entregue

- Publicação dos Resultados da Pesquisa - Entregue

- Declaração de Responsabilidade, Direitos e Obrigações - Entregue

- Declaração de Recrutamento - Entregue

- Orçamento Financeiro Detalhado - Entregue

- Declaração de possuir Currículo na Plataforma Lattes - Profa Dra Diná de Almeida da Cruz - Entregue

- Curriculum Vitae - Pesquisadora Principal e Orientadora - Entregue

O Comitê de Ética em Pesquisa, solicita que:

a. Informar imediatamente relatório sobre qualquer evento adverso ocorrido

b. Comunicar qualquer alteração no projeto e no TCLE.

c. Elaborar e apresentar ao CEP os relatórios parcial e final sobre a pesquisa.

Situação: Protocolo Avaliado e Aprovado em Reunião Ordinária no dia 12 de maio de 2009.

São Paulo, 12 de maio de 2009.

Pedro lpan ly

Cooplenador CEP

CRM 55073

Av. Dr. Dante Pazzanese, 500 • Ibirapuera • São Paulo - SP·CEP: 04012-909 • Fone: (11) 50856040 • E-mail: cep@dantepazzanese.org.br

FORM 001IDPC Mar/09 rev.1 


\section{ANEXO II}

\section{Termo de Consentimento Livre e Esclarecido}

\section{I - Dados de Identificação do sujeito de pesquisa}

Nome do participante

Documento de Identidade $\mathrm{N}^{\circ}$ SEXO M $\square \quad F \square$

Data de Nascimento I 1

Endereço

Cidade CEP Telefone

II - Dados sobre a pesquisa científica

TÍTULO DA PESQUISA: Características do sono de pacientes com insuficiência cardíaca PESQUISADOR: Mariana Alvina dos Santos

CARGO/FUNÇÃO: Enfermeira

INSCRIÇÃO CONSELHO REGIONAL:105.649

\section{LOCAL DA PESQUISA:}

\section{AVALIAÇÃO DO RISCO DA PESQUISA:}

Sem risco $\square \quad$ Risco mínimoX $\quad$ Risco baixo $\square \quad$ Risco médio $\square \quad$ Risco maior $\square$

(probabilidade de que o indivíduo sofra algum dano como conseqüência imediata ou tardia do estudo)

DURAÇÃO DA PESQUISA: 12/2008 a 03/2010

III - Registro das explicações do pesquisador ao paciente ou seu representante legal sobre a pesquisa

Pesquisa: padrão de sono em pacientes com insuficiência cardíaca

1) Um sono satisfatório é um dos principais meios para que possamos desempenhar as atividades do dia-a-dia com qualidade. Sendo assim, os objetivos desta pesquisa são verificar o padrão de sono em pacientes com insuficiência cardíaca.

2) Para isto, você irá responder 3 questionários com perguntas sobre o seu sono, seu dia-adia e outras questões relacionadas a outros sintomas. 
Mariana Alvina dos Santos

3) Os resultados deste estudo ajudarão a elaboração de intervenções para um sono de melhor qualidade em pacientes com insuficiência cardíaca, melhorando assim sua qualidade de vida.

\section{IV - Esclarecimentos dados pelo pesquisador sobre garantias do sujeito da pesquisa}

1) A qualquer tempo vocês, participantes deste estudo, poderão ter acesso às informações sobre a pesquisa, seus procedimentos, riscos e benefícios, inclusive para tirar dúvidas pelos telefones/endereços abaixo citados.

2) A participação nesta pesquisa é voluntária e o indivíduo que participar poderá retirar o consentimento a qualquer momento e, portanto, pode deixar de participar do estudo, sem acarretar prejuízos ao tratamento médico.

3) Os participantes não serão identificados garantindo-se o sigilo das respostas, que permanecerão confidenciais. Este estudo não trará riscos ou prejuízos ao seu tratamento.

V - Informações de nomes, endereços e telefones dos responsáveis pelo acompanhamento da pesquisa, para contato em caso de intercorrências clínicas e reações adversas

Declaro que, após convenientemente esclarecido pelo pesquisador e ter entendido o que me foi explicado, consinto em participar do presente Projeto de Pesquisa.

São Paulo, de de 20

Assinatura do sujeito de pesquisa

Escola de Enfermagem da Universidade de São Paulo Responsável pela pesquisa: Diná de $\mathrm{A} L \mathrm{M}$ da Cruz Av. Dr ${ }^{\circ}$ Enéas de Carvalho Aguiar, 419 sala 314 Telefone: (11)-3061 7544

Escola de Enfermagem da Universidade de São Paulo Pesquisadora: Mariana Alvina dos Santos

Av. Dr ${ }^{\circ}$ Enéas de Carvalho Aguiar, 419 sala 314

Telefone: (11)-9475 7261 